Andrews University

Digital Commons @ Andrews University

1996

\title{
The Relationship of Student Retention to Teacher/Student Personality Types at Summit Christian College
}

C Joseph Martin

Andrews University

Follow this and additional works at: https://digitalcommons.andrews.edu/dissertations

Part of the Higher Education Commons, and the School Psychology Commons

\section{Recommended Citation}

Martin, C Joseph, "The Relationship of Student Retention to Teacher/Student Personality Types at Summit Christian College" (1996). Dissertations. 560.

https://digitalcommons.andrews.edu/dissertations/560

https://dx.doi.org/10.32597/dissertations/560

This Dissertation is brought to you for free and open access by the Graduate Research at Digital Commons @ Andrews University. It has been accepted for inclusion in Dissertations by an authorized administrator of Digital Commons@ Andrews University. For more information, please contact repository@andrews.edu. 


\section{Andrews \$university}

Seek Knowledge. Affirm Faith. Change the World.

Thank you for your interest in the

\section{Andrews University Digital Library of Dissertations and Theses.}

Please honor the copyright of this document by not duplicating or distributing additional copies in any form without the author's express written permission. Thanks for your cooperation. 


\section{INFORMATION TO USERS}

This manuscript has been reproduced from the microfilm master. UMI films the text directly from the original or copy submitted. Thus, some thesis and dissertation copies are in typewriter face, while others may be from any type of computer printer.

The quality of this reproduction is dependent upon the quality of the copy submitted. Broken or indistinct print, colored or poor quality illustrations and photographs, print bleedthrough, substandard margins, and improper alignment can adversely affect reproduction.

In the unlikely event that the author did not send UMI a complete manuscript and there are missing pages, these will be noted. Also, if unauthorized copyright material had to be removed, a note will indicate the deletion.

Oversize materials (e.g., maps, drawings, charts) are reproduced by sectioning the original, beginning at the upper left-hand comer and continuing from left to right in equal sections with small overlaps. Each original is also photographed in one exposure and is included in reduced form at the back of the book.

Photographs included in the original manuscript have been reproduced xerographically in this copy. Higher quality 6 " $\times 9$ " black and white photographic prints are available for any photographs or illustrations appearing in this copy for an additional charge. Contact UMI directly to order.

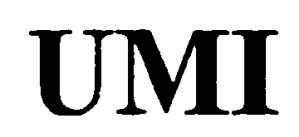

A Bell \& Howell Information Company 300 North Zeeb Road, Ann Artor MI 48106-1346 USA $313 / 761-4700 \quad 800 / 521-0600$ 


\title{
Andrews University
}

School of Education

THE RELATIONSHIP OF STUDENT RETENTION TO TEACHER/STUDENT PERSONALITY TYPES AT SUMMIT CHRISTIAN COLLEGE

\author{
A Dissertation \\ Presented in Partial Fulfillment \\ of the Requirements for the Degree \\ Doctor of Education
}

by

c. Joseph Martin

August 1996 
OMI Number: 9708085

UMI Microform 9708085

Copyright 1996, by UMI Company. All rights reserved.

This microform edition is protected against unauthorized copying under Title 17, United States Code.

\section{UMI}

300 North Zeeb Road

Ann Arbor, MI 48103 


\title{
THE RELATIONSHIP OF STUDENT RETENTION TO TEACHER/STUDENT PERSONALITY TYPES AT SUMMIT CHRISTIAN COLLEGE
}

\author{
A dissertation \\ presented in partial fulfillment \\ of the requirements for the degree \\ Doctor of Education
}

by

C. Joseph Martin

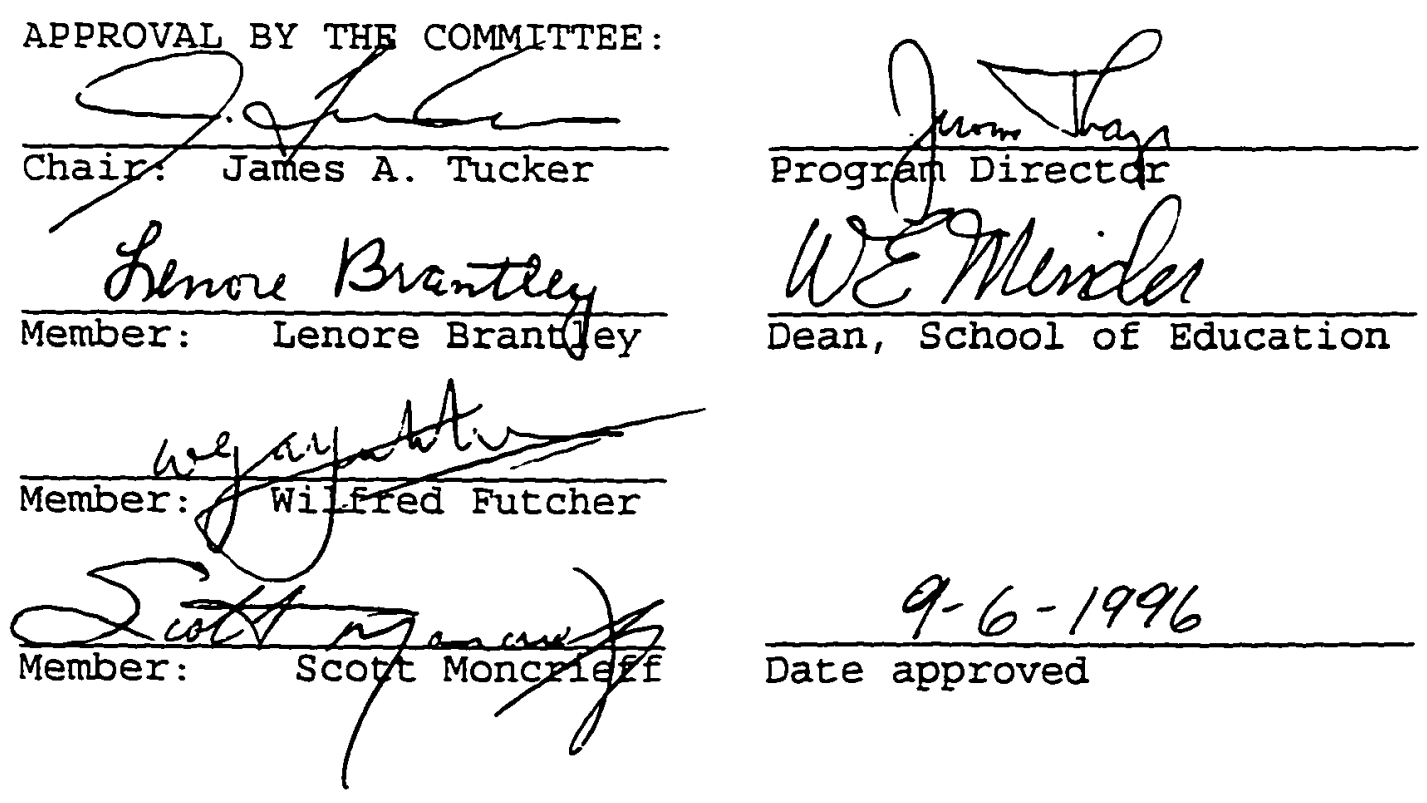




\section{ABSTRACT \\ THE RELATIONSHIP OF STUDENT RETENTION TO TEACHER/STUDENT PERSONALITY TYPES AT SUMMIT CHRISTIAN COLLEGE}

by

c. Joseph Martin

Chair: James Tucker 


\title{
ABSTRACT OF GRADUATE STUDENT RESEARCH \\ Dissertation
}

\author{
Andrews University \\ School of Education
}

\section{Title: THE RELATIONSHIP OF STUDENT RETENTION TO TEACHER/STUDENT PERSONALITY TYPES AT SUMMIT CHRISTIAN COLLEGE}

Name of researcher: c. Joseph Martin Name and degree of faculty chair: James Tucker, Ph.D. Date completed: August 1996

For the past 3 decades, retention studies have emerged as being of significant importance to the smaller colleges and universities, especially the private colleges and universities, including summit christian college. With the decline in the high-school population, which was predicted to occur in the mid-70s, retention was going to be of even more importance to the smaller educational institutions. All of this pointed toward a time when colleges would have to compete for the high-school graduate in a more aggressive manner. It was possible that unless new ways of coping with the drop-out rate were 
initiated, a number of smaller schools would go out of business.

The purpose of this study was to identify the relationship between personality types of faculty members and the personality types of students at summit christian College and to determine if there is any relationship between faculty personality types and student personality types and student retention.

The data for this study came from the Myers-Briggs Type Indicator and the Please Understand Me test (an adaptation of the Myers-Briggs Temperament Traits test) . The tests were administered to all full-time faculty members (M-BTI) employed in 1990 and 1991 and to all new students enrolled in the Freshmen orientation course in 1990 (PUM) and 1991 (M-BTI). The research was conducted over the 2-year period; there was a response rate of $100 \%$. The results of the study indicate that the Sensing-Judging, Intuitive-Feeling, and Intuitive-Thinking personality types of faculty members are correlated with the Sensing-Judging, Sensing-Perceptive, IntuitiveFeeling, and Intuitive-Thinking student personality types represented at summit Christian college in determining which students are more apt to remain in college and which ones are more likely to drop out. The combinations of Sensing-Judging with, Intuitive-Feeling, and IntuitiveThinking faculty personality types correlate positively with the Sensing-Judging students in retention. No other 
combination of faculty personality types correlates positively with the retention of the other three student personality types.

Recommendations for institutional policy and practice are included in the discussion of the results. 
TABLE OF CONTENTS

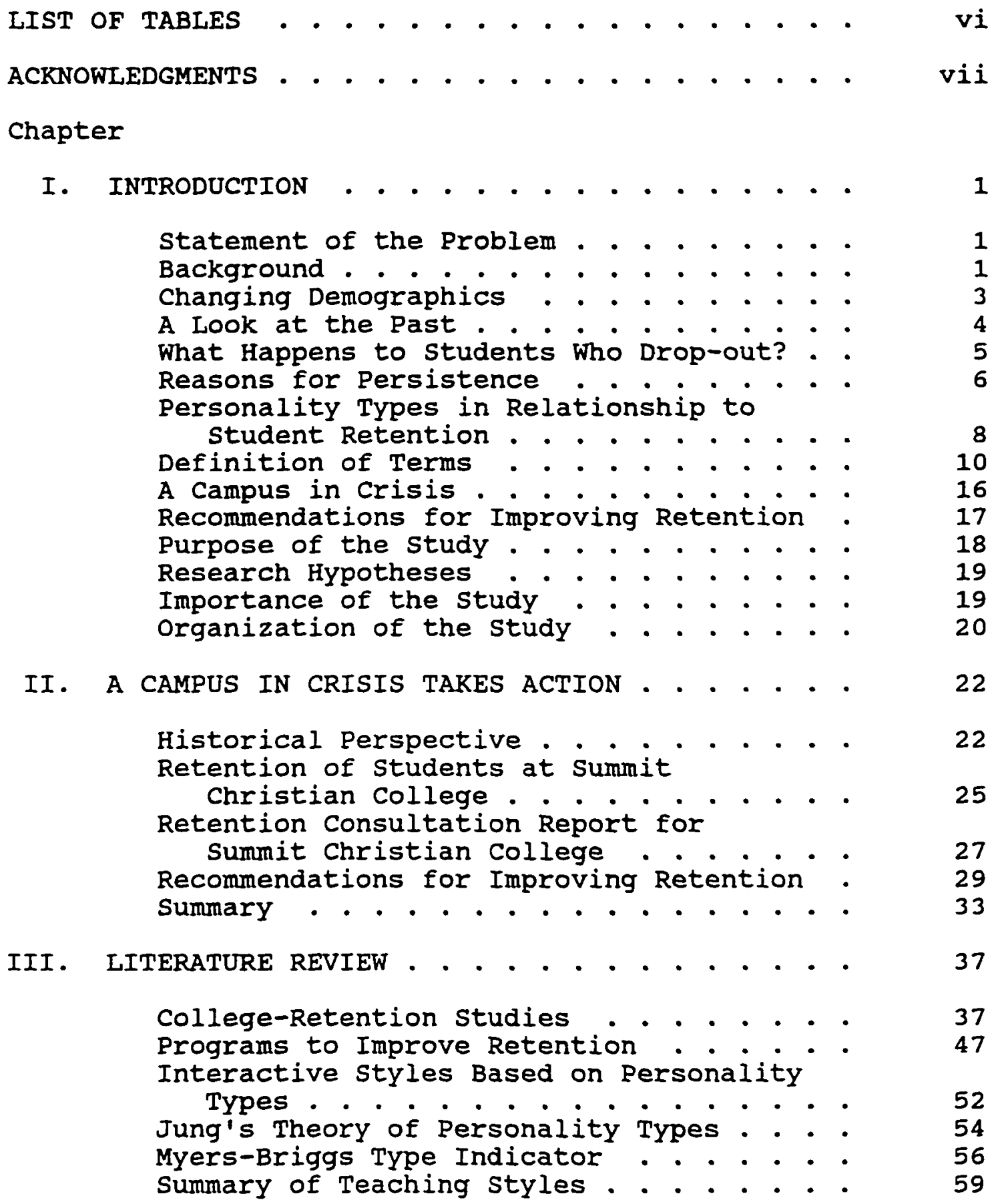

iii 
Understanding Characteristics of

Learning Styles.......... . . 61

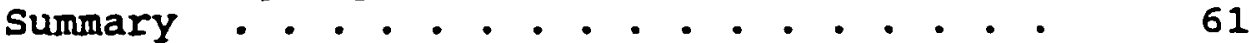

IV. METHODOLOGY . . . . . . . . . . . . 62

Type of Research . . . . . . . . . . 62

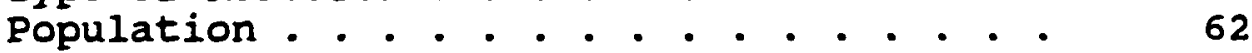

Instrumentation . . . . . . . . . . 62

Administration .............. . . 63

Development . . . . . . . . . . . . 64

Reliability . . . . . . . . . . . . . 64

Validity . . . . . . . . . . . . . 67

Procedures . . . . . . . . . . . . . . 68

Null Hypotheses and Analysis Methods . . . 69

Iimitations . . . . . . . . . . . 70

Summary . . . . . . . . . . . . . . 71

V. RESULTS . . . . . . . . . . . . . . . 72

Introduction .............. . . 72

Distribution of Respondents . . . . . . 72

Faculty Distribution . . . . . . . 72

Student Distribution . . . . . . . . 75

Testing the Null Hypotheses . . . . . . 77

Summary ................. 80

VI. SUMMARY, FINDINGS, CONCLUSIONS, IMPLICATIONS AND DISCUSSION FOR FURTHER RESEARCH • • • . • 82

Introduction ............. 82

Purpose . . . . . . . . . . . . . 82

Structure ................. . . 83

Methodology . . . . . . . . . . . . 84

Issues Raised . . . . . . . . . . . . . 85

Major Findings and Conclusions. . . . . 87

Testing the Hypotheses... . . . . . . 88

Conclusions . . . . . . . . . . . . 89

Discussion . . . . . . . . . . . . . 90

Convergent Theories Related to 90

Divergent Theories Related to

Implications of the study for sumit

Christian College. . . . . . . . . . . 91

Specific Recommendations for Summit
Christian College. . . . . . . . 92

Limitations and Recommendations for
Further Study . . . . . . . . . 94

Recommendations for Further Research . . . 95

iv 
Appendices

A. THE KEIRSEY-BATES TEMPERAMENT SORTER . . . 101

B. COLLEGE SUCCESS STRATEGIES . . . . . . . 106 REFERENCE LIST . . . . . . . . . . . . . . 135

VITA. . . . . . . . . . . . . . . . . . 140 


\section{LIST OF TABLES}

1. Factors Contributing to a Successful and satisfying College Career . . . . . . . . 8

2. Percentage of Graduates From Summit Christian College by Cohort Group 1979-1992... . . . 25

3. Predicted Percentage of Decline in HighSchool Graduating Seniors (1978-1995), Great Lakes Region 1990 . . . . . . . . . 26

4. Sixteen Personality Types Identified . . . . . . 58

5. Internal Consistency Derived From ProductMoment Correlations of $X$ and $Y$ Continuous Scores with Spearman-Brown Prophecy Formula correction ... . . . . . . . .

6. A Comparison of Internal Consistency of Type Categories Using Estimates from Phi Coefficients and Tetrachoric Correlations, all Corrected Using the Spearman-Brown Prophecy Formula . . . . . . . . . . . .

7. Demographic Distribution of the Faculty $(\mathrm{N}=21)$. . . . . . . . . . . . . 73

8. Distribution of Faculty by Personality Types . . . . . . . . . . . . . . .

9. Distribution of Student Personality Types Tested (in percentages) for Freshmen only, 1990 and 1991 Combined . . . . . .

10. Chi-Square Contingency Table Demonstrating Relationship Between Personality Types and Retention Rate for Students . . . . . . .

11. Discriminant Analysis for $\mathrm{SJ}, \mathrm{NT}$, and $\mathrm{NF}$ Faculty Members with SJ students 


\section{ACKNOWLEDGMENTS}

I appreciate the faculty, staff, and students at Summit Christian College for the acceptance and support offered to me during the course of my studies. I have received a great deal of encouragement from everyone, but especially from the students in my various classes. Their faith in my abilities has acted as a catalyst to push me ahead with my work when I might have willingly given in to the pressure to quit.

My special thanks go to Dr. James Tucker, my dissertation director. His ability to be critical and yet warm has been greatly appreciated. A very special debt of appreciation goes to Dr. W. G. A. Futcher, the statistician on my dissertation committee. His skill as a teacher in my first statistics course at Andrews University opened up the door to a field that had been closed to me since my failure in high-school algebra.

Several other people have been important in my work toward a doctoral degree at Andrews University. My primary academic advisor, Dr. Rick Kosinski, set the tone for my work in Counseling and Human Development. While he was much younger than I am, I still looked to him as a mentor in my field of study. I respected his level of academic

vii 
achievement and his skill in making everything seem practical.

I would also extend my appreciation to Dr. Lenore Brantley. Dr. Brantley has shown a warm and caring spirit assisting me while serving on the dissertation committee. In addition, appreciation is offered to Dr. Scott Moncrieff who was recruited from outside the Department of Education to serve on my committee. I can only imagine how much effort this takes to try to get excited about a topic in another field of study.

I need to express special appreciation to Dr. Carolyn Arthur at Taylor University, Fort Wayne Campus, for her patience in helping in the editing of my dissertation. Her wise counsel was tremendously important in getting the technological part of the dissertation completed. I especially appreciated her ability for detail analysis. Without her help, the dissertation would have been almost impossible to complete.

Two other people who need to be recognized are Mrs. Lorraine Roth and Mrs. Caroline Simmons, administrative assistants to the Vice President at Taylor University Fort Wayne. Their cheerful dispositions and willingness to help with the typing at a moment's notice all contributed to getting the job done.

A final word of appreciation goes to my wife Shirley. For over 45 years she has been my favorite cheerleader. She knows how to encourage me with words of

$$
\text { viii }
$$


wisdom and hope. Her patience over the years while I have pursued a variety of academic degrees has been superb. Her love knows few limits when it comes to being with me in every phase of my life. She is the gentle force that has empowered me throughout our marriage and life together. 


\section{CHAPTER I}

\section{INTRODUCTION}

\section{Statement of the Problem}

A set of common questions raised by those doing research in student retention is stated by Cope (1978) who asked, "Why do students leave college, why do they stay, and what appears to make the difference?" (p. 1). Several findings of interest from studies in retention were as follows:

1. Approximately $40 \%$ of entering freshmen did not graduate with a baccalaureate degree in the normal 4 years commonly required to obtain such a degree.

2. Another $40 \%$ did gain a baccalaureate degree.

3. An additional $20 \%$ delayed their baccalaureate degree until later. These findings have remained constant over the past 4 decades (Cope, 1978, p. 3).

\section{Background}

With a smaller number of high-school students graduating each year, retention studies have become increasingly important to a wide variety of academic institutions (Beal \& Noel, 1980, p. 1). Colleges and universities are competing to recruit students from a 
declining pool of potential applicants. For example, 20 years ago when there was a large pool of potential applicants, many institutions of higher education did not appear to be interested in attrition and retention rates. State schools and land grant universities did not spend a great deal of effort in admissions procedures; they simply maintained or increased total enrollments without much effort, and hardly anyone asked, "Where have all the students gone?" This is changing now and many schools find it necessary to build stronger admissions programs. In a presentation at the National Conference of the American Counseling Association, Martin, Berkey, and Gribbin (1982) discussed retention in a small college subtitled, "A Study and Proposal for survival". There were 125 college administrators and admissions counselors present for the discussion, representing large universities such as the University of Nepraska. Many of these schools were there because the admissions process and retention maintenance were new to them. According to Beal and Noel (1980), retention has become important in order to meet the problem of declining enrollment. They go on to suggest that, "if schools can retain more students once they are admitted, then enrollment will hold steady or decrease at a slower rate" (p. 1). 
Following the lead of Alexander Astin, most of the research in student retention has focused on a wide range of institutional practices:

1. recruitment and admissions policies

2. residence requirements

3. allocation of financial aid

4. selection of students for residence halls

5. availability of jobs on campus

6. grading practices

7. granting of leaves of absence

8. transfer policies

9. establishment of work-study programs. (Astin, 1975, pp. ix-x)

As the concern for student retention increases, colleges and universities will have to work harder to retain the students they have already recruited and enrolled.

\section{Changing Demographics}

There are several ways of addressing the issue of demographic data as a background for understanding student retention. Friday (1988) stated that "students entering college today have little in common with the freshman of the first half of this century" (p. 1). The makeup of today's student body is significantly different than it was in the first half of this century. Today there are more women in our entering classes, more multicultural students, a larger percentage of first-generation college students, a growing number of international students, an increased number of economically and culturally disadvantaged students, and there are other population groups (Friday, 1988, p. 1). For example, in the fall of 
1991, the enrollment statistics for summit Christian College included three American Indians or Alaskan Natives, two Asian or Pacific Islanders, 21 Blacks (nonHispanic), 20 of unknown origin, and 357 white (nonHispanic) students. The total student body consisted of 233 women and 177 men from 19 states and several foreign countries. Of the 410 students, 114 were considered to be non-traditional (over age 25).

A rather pessimistic view of retention was stated by the President of Marietta College in Marietta, Ohio, in the fall of 1961: "Look to your left and look to your right, and four years from now neither of the people on either side of you will be here when you graduate" (Gardner \& Jewler, 1985, p. xii). This is another way of recognizing the consistency of attrition over a period of decades. Historically, the assumed attrition was simply stated as a matter of fact without any plan to change the retention rate.

\section{A Look at the past}

In the past 40 years the focus of retention

efforts has shifted from what some have called

"descriptive studies" to those addressing the "fit" between the student and a particular institution. Then the focus shifted again, stressing efforts to understand the type of student who dropped out and the experiences he 
or she was having as a college student (Beal \& Noel, 1980, p. v) .

Beginning with the 1980s, yet another shift in emphasis became evident. Studies began to focus on the quality of faculty-student interaction. A greater emphasis was placed on the type of degree programs that was being offered to students. Concern was expressed about the value of academic courses in meeting the educational needs of students facing the new demands of the working world. A great deal of concern was expressed about residence hall living. Colleges and universities began to allow students more freedom in decorating and individualizing their rooms. There was an increased concern about providing financial assistance to more students. "The emphasis has clearly shifted to improving the quality of higher education in order to retain the confidence of students" (Beal \& Noel, 1980, p. v).

\section{What Happens to students Who Drop-out?}

"Our studies have revealed that most colleges know very little about why their students withdraw" (Cope \& Hannah, 1975, p. 7). For the $40 \%$ to $50 \%$ of students who drop out of college and never earn degrees, the cost is high. Leaving college can mean a substantial loss to the student in future earnings. Cope and Hannah report that it also takes many years to make up for the cost of the tuition, room and board, and lost income for each year the 
student is in school. In addition, many students who do not complete a degree program experience psychological loss. They may be disappointed in themselves and at the same time face the disappointment of family and friends. They may experience a sense of shame associated with not being able to complete what they started (Cope \& Hannah, 1975, p. 6) .

The student who drops out of college is not the only one who loses; so does the college or university. Not only is there the loss to the institution in terms of tuition revenue, but the substantial investment in time and money to recruit the student is lost as well, not to mention the loss of value in not being able to claim graduate success. "The graduate becomes a credit, an alumnus, or alumna, a representative. The non-graduate erodes institutional capacity and credibility" (cope \& Hannah, 1975, p. 6).

\section{Reasons for Persistence}

To better discover how students succeed in college, it is helpful to understand their environmental background and experiences before coming to college. These factors include gender, age, race, prior academic experiences, personal motivation, parental education level, economic factors, personal expectations, and definition of success. "Family influence is especially important" (Upcraft, Garland, \& Finney, 1984, p. 9). 
Students feel capable of persisting in college if they know their families stand behind them with emotional support and an understanding of their personal problems. Supportive, caring parents are helpful to college students in their career decisions as well (Upcraft et al., 1984, p. 9) .

At the same time, it is important to understand the influence the college exerts on the student it has enrolled. Upcraft et al. suggested that some of the positive characteristics of the college climate should include understanding:

1. The goals and purposes of an institution

2. The institutional climate and characteristics

3. Congruence between the individual and the environment

4. Peer group influence

5. Living in a residence hall

6. Making close friends

7. Belonging to student organizations

8. Involvement in cultural activities

9. Involvement in social activities

10. Using the college facilities

11. General participation in extracurricular and campus life (Upcraft et al., 1984, pp. 10-11).

Walter and siebert (1987) suggested that there are many reasons for college students remaining in school until graduation. Table 1 presents students' reasons for 
persisting, in order of importance. The data in this table seem to be consistent with the emphasis on personal relationships as noted by much of the current research.

Table 1

Factors contributing to a successful and satisfying College Career

\begin{tabular}{ll}
\hline Reasons & $\%$ \\
\hline Personal contacts with students & 80 \\
Personal contacts with faculty and staff & 78 \\
Time spent on activities outside of class & 76 \\
Ability to organize tasks and use of time & 73 \\
Work experience during college/summers & 72 \\
Health, attitude, eating, and drinking & 63 \\
Social life on campus & 62 \\
Sense of direction in career life planning & 56 \\
Availability of financial resources & 52 \\
\hline
\end{tabular}

Note. From student Success: How to succeed in college and still Have Time for Your Friends ( $p$. 5) by Tim Walter and Al Siebert, 1987, Chicago: Holt, Rinehart and Winston, Inc.

\author{
Personality Types in Relationship \\ to student Retention \\ According to data from Walter and siebert (1987),
} two of the most important factors in retention are the interpersonal relationships between students and the interaction between faculty and students. Because little research has been done in the area of faculty personality types and student personality types and retention, the 
researcher decided to deal with this particular dimension of faculty/student interaction.

The purpose of this study was to identify the relationship between personality types of faculty members and the personality types of students at summit Christian college and to determine if there is any relationship between faculty/student personality types and student retention.

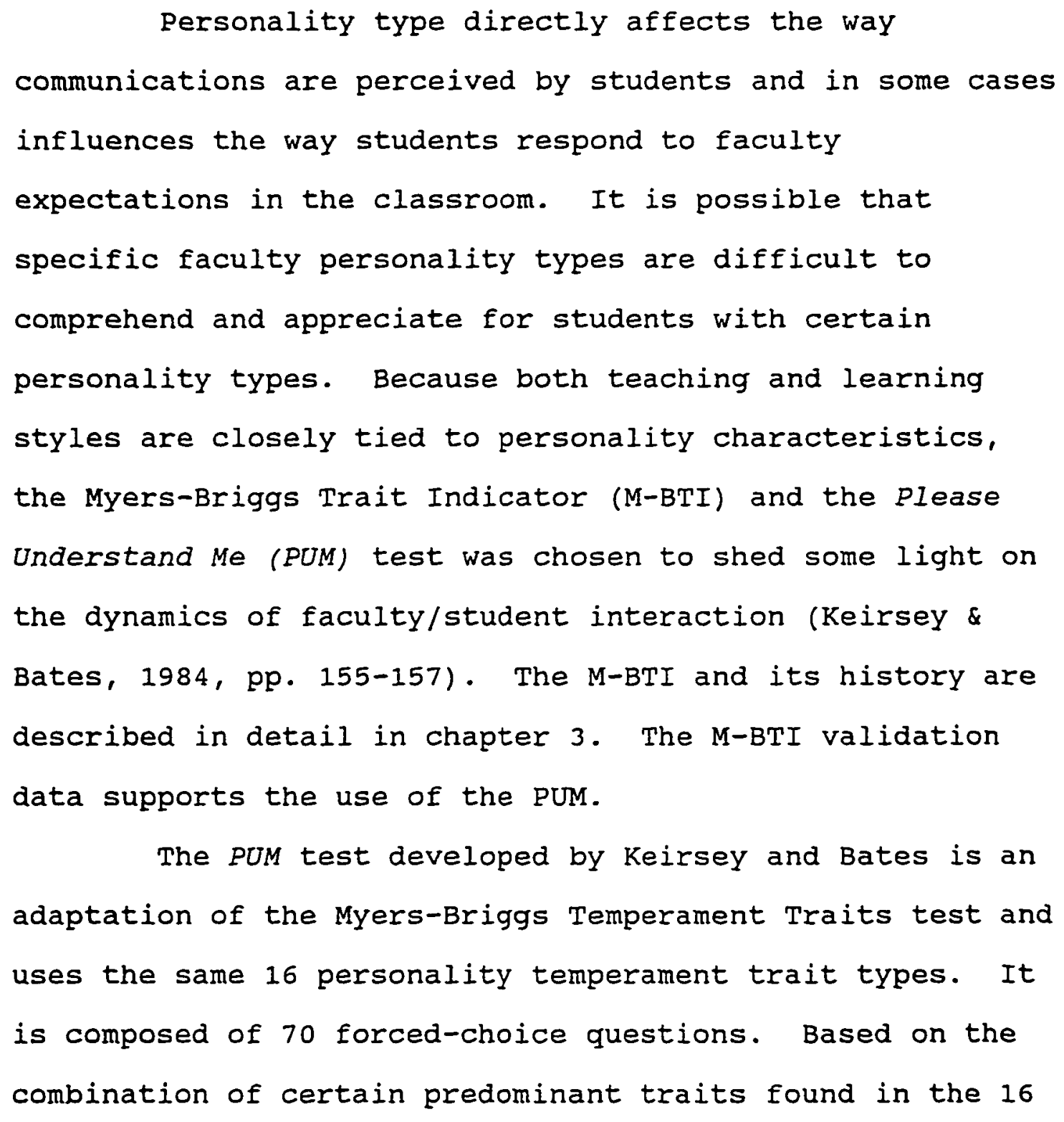


types, Keirsey and Bates have identified four personality types that are related to faculty/student interaction, the Sensing-Perceiving (SP), the sensing-Judging (SJ), the Intuitive-Thinking (NT), and the Intuitive-Feeling (NF). Following is a brief description of the four basic learning styles as described by Keirsey and Bates (1984) that are typical of the general population.

\section{Definition of Terms}

The four primary learning styles for the general population are as follows:

The SP temperament (38\% of the population) needs to belong, to be useful to society, and tends to serve others. Persons with this temperament tend to be impulsive, to become restless when there are too many constraints. They tend to test the limits, have a strong desire to be a free spirit, and a compulsion to wander, to sever social ties easily. They tend to be action oriented, exciting, having the power to do something, being spontaneous. They might enjoy racing, surfing, or being a soldier of fortune, a magician, and the performing artist.

Approximately $4 \%$ of the total SP population are in the teaching profession from grade school through graduate school. According to Myers and McCaulley (1985), 6.7\% of the total SP personality types become college faculty members in both 2-year and 4-year colleges. SP faculty 
members tend to place a great deal of value on helping the student become more spontaneous. In fact, spontaneity is important in the teaching process itself. These teachers cherish freedom and creativity in teaching and try to develop this in their students. They have the potential of being exciting teachers, offering a wide variety of experiences for the student.

The SP faculty members are performers and like to be the star of the classroom; they play to their audience. They tend to favor teaching in the arts, crafts, sports, drama, music, and recreation. The SP teacher usually does not stay in teaching very long.

The SP student is found in approximately $38 \%$ of a typical classroom setting. The SP student learns best by studying those subjects that seem to be practical and have immediate rewards. They hunger for action and therefore tend to dismiss the theoretical as not being relevant. These students are the "performers" who enjoy play and adventure. They seek immediate gratification. They need to learn by hands-on experience. They tend to thrive on competition and love to take risks, living on the edge of danger. The SP gravitates toward music, drama, art, crafts, mechanics, construction, or anything that involves active participation.

The SJ temperament ( $38 \%$ of the population) needs to belong, to be useful to society, and tends to need to serve others. The SJ needs rules and structure in order 
to maintain status in society. Tradition is important to the SJ. If there is no tradition, the SJ will tend to develop one. Position and titles are important to persons with SJ temperaments, and they often take on leadership roles.

The SJ faculty member is found in $54 \%$ of the teaching population (from grade school through graduate school. At the 2-year and 4-year college level that number decreases to 32.9\% (Myers \& McCaulley, 1985, p. 134). SJ teachers value the growth of responsibility in their students. Education is seen as being important for the development of basic academic skills needed for the market place. They will have a well-organized classroom with a well-planned curriculum which will be carried out in a sequential pattern. They tend to prefer obedient students. They are much less patient with the nontraditional student who does not conform to the normal learning routine. The SJ faculty member seems to prefer working with SJ students. The SJ teacher tends to teach in agriculture, clerical fields, business, sports, social science, political science, homemaking, history, and geography. He or she tends to use recitation, drills, composition, tests/quizzes, and demonstrations as part of his/her teaching methods. He or she tends to stay in teaching for a long period of time.

Approximately $38 \%$ of the students in a typical classroom are SJ personality types. The SJ students learn 
best in a classroom where there is well-defined structure. They have a tendency to want to please teachers simply because they are the teachers. SJ students enjoy workbook-type assignments where the lessons are presented in a logical, sequential pattern. These students will tend to be conscientious and do their best when they receive clear instructions with well-defined directions to follow.

The NT personality type (12\% of the population) seeks to be competent. These individuals love intelligence and in some cases feel compelled to acquire it. They feel a need to master understanding of all objects and events in their surroundings. NTs often have a sense of always being on the verge of failure. They find it difficult to accept the fact that they can do things well. They are always seeking to improve. Because they tend to reach toward perfection and since no one can live up to those standards, they are often seen as being too demanding in their expectations of themselves and others.

The NT faculty type is found in $10 \%$ of the teaching population (from grade school through graduate school). That percentage increases at the 2-year and 4year college level to $27.4 \%$ (Myers \& McCaulley, 1985, p. 134). NT teachers place a great deal of value on developing the growth of knowledge and skill in their teaching methods. They focus on developing the 
intellectual aspect of the classroom environment. They tend to enjoy stretching their students, inspiring them to learn all that is possible, both inside and outside the classroom. They tend to enjoy teaching in philosophy, science, technology, communications, mathematics, and linguistics. The favorite teaching method of the NT faculty member includes lecturing, testing, writing compositions, doing projects, and reports. They stay in teaching for an average amount of time.

Those with an NF personality type $112 \%$ of the population) are concerned with seeking to understand who they are. They often ask the question, "How can I become the person I want to be?" It is important for the NF to live a life that is significant to the self as well as others. These individuals tend to spend a great deal of time and effort in relationships that are important to them. A majority of writers come from this group. For the NF, the search for meaning is the driving force in his or her daily life. The NF has a great desire to transmit ideas and attitudes to the populace.

The NF personality type is found in $32 \%$ of the teaching population (from grade school through graduate school). This number increases slightly at the 2-year and 4-year college level to $33.9 \%$ (Myers \& McCaulley, 1985, p. 134). NF teachers place their primary emphasis on the growth of personal identity and integrity in their students. They are most often seen by the students as 
being the most charismatic of all teaching types. students tend to feel that the NF faculty member is genuinely interested in them, in their social and intellectual development. They often are capable of helping students find talents in themselves which they had not seen before. They are in touch with the climate of the classroom and can change a lesson plan at any given time to meet the needs of their students. Because they tend to be unconventional in their teaching style, they often can adjust to the unconventional student. The NF faculty member tends to interact with each individual student in the class, which can be very difficult emotionally for the teacher. He or she tends to teach in the areas of social science, theater, music, foreign languages, speech, and theology. Favorite teaching methods include group projects, interaction, discussion, shows, simulations, and games. These teachers tend to stay in the teaching field for a long period of time. The NF learning style consists of $12 \%$ of students in a typical classroom. NF students are people with a hunger to learn more about themselves. These students have a need to be known by name as well as to be recognized as being individuals. They often need to be recognized for things they do well. Personal notes by the teacher can provide a powerful motivation to do better on the next paper. Negative remarks from a teacher can provoke rebellion or inaction in the NF student. The NF 
is often seen as charismatic, empathic, dramatic, and the idealist. NF students tend to choose the liberal arts over science and technology. They tend to learn best in one-on-one interaction with the teacher. They will be responsive to teachers who are accepting and nourishing, but can be hurt easily by sarcasm and ridicule (Keirsey \& Bates, 1984, pp. 121-165).

\section{A Campus in Crisis}

Over a 10-year period, Summit Christian College had an alarming attrition rate which averaged $78 \%$ and ranged from a high of $86.4 \%$ in 1984 to a low of $70.7 \%$ in 1990.

Because the national average for the percentage of graduates from a traditional 4-year undergraduate program is consistent at approximately $50 \%$ of entering freshmen, it seemed important to understand what was happening at Summit Christian College.

In 1989, Sumit Christian College contracted with the Noel/Levitz Centers for Institutional Effectiveness and Innovation, Inc., to serve as retention consultants for the institution. The work was completed in December, 1990, with an on-site visit by Michael Hovland, Senior Consultant with the Noel/Levitz Centers, Inc. In agreement with the Beal and Noel studies in 1980, he said:

With a relatively strong academic program in place, I feel that Summit Christian will make the most important impact in improving retention by focusing on issues of quality of life and community. In addition, retention 
can be improved by increased attention to academic advising, academic support services, career development, and other aspects of student growth and development. (Hovland, 1990, p. 1)

\section{Recommendation for Improving Retention}

Hovland (1990) suggested to the administration and faculty that the goal of a college retention effort is to build on the current strengths of an institution, and to see that as many students as possible are impacted by people, programs, and services that promote their success and persistence in college ( $p .1)$. He indicated several things that needed to be addressed at summit Christian college in order to improve retention. One of Hovland's most important recommendations was to improve tracking of student persistence patterns. Development of a greater sense of community among students, faculty, and staff was also seen as a critical need. He also suggested that the college needed to focus on getting students "started right" on their academic journey. Assisting underprepared students to deal with college life was also addressed (pp. 7-14). Hovland recommended providing a good career counseling program for those students who had not chosen a major.

Several other recommendations by Hovland (1990) addressed specific issues. With a non-traditional population of approximately $33 \%$, it was suggested that Summit Christian college needed to integrate non-traditional students more fully into campus life. Since chapel was seen as an important aspect of the life of the college, Hovland 
stressed the importance of finding a way to develop support for chapel and other religious activities on campus. He also recommended that the college needed to cut through "red tape" for students. Finally, it was suggested that the institution needed to develop an effective early warning/early alert system to identify students who might be at risk of leaving college either because of academic problems or problems of a more personal nature (pp. 7-14).

\section{Purpose of the study}

The purpose of this study was to identify the relationship between personality types of faculty members and the personality types of students at sumit christian College and to determine if there is any relationship between faculty/student personality types and student retention. With an awareness of the personality types of faculty members and the personality types of students, the institution would be in a better position to implement strategies mentioned by Hovland (1990) for cutting the attrition rate.

The research question guiding this study was:

Does a relationship exist between the faculty personality types and the student personality types indicated in the Myers-Briggs Trait Indicator and the Please Understand Me tests and the retention rate at summit Christian college, and if so, how does this relationship affect retention? 


\section{Research Hypotheses}

In order to answer the research question noted above, two research hypotheses were formulated.

Hypothesis \#1: There is a significant relationship between student personality types and the probability of retention.

Hypothesis 2: There is a combination of faculty personality types that significantly discriminates between the retention and attrition groups of students.

\section{Importance of the study}

This study may be of particular interest and importance to administrators at summit Christian college as they continue to explore the high attrition rate at their institution. It may also prove to be of value to administrators of small, private colleges and universities similar in size and mission to summit Christian college which may be experiencing difficulty in retention. By identifying the faculty personality types and the student personality types that may be important to the stabilization of a student population and retention of enrolled students, it may be possible to increase the student population with little increase of financial outlay in the admissions process.

It is hoped that this study will also make an important contribution to the field of college retention studies by creating new insights into the impact of 
personality factors on student success in completing a college education.

\section{organization of the study}

This dissertation has five additional chapters, organized in the following manner:

Chapter 2 contains an overview of the crisis that existed at Sumit Christian College as evaluated by Michael Hovland, Senior Consultant for the Noel/Levitz Centers, Inc. This chapter chronicles the problem that had existed for over a decade, had been studied in many different ways, exposed to outside consultants as well as internal studies, to little success. This chapter demonstrates the heart of the problem at sumit Christian college.

Chapter 3 contains a review of the relevant literature. It also contains a description of the MyersBriggs Trait Indicator and the Please Understand Me tests, which is an adaptation of the Myers-Briggs Type Indicator used to evaluate personality types for faculty and students. Chapter 4 outlines the design and methodology used in the study. This chapter also contains a description of the population and the procedures used in data collection and analysis. The chapter delineates the process used in gathering data from both students and faculty, and concludes with a statistical analysis of the results.

Chapter 5 includes a presentation and analysis of the findings of the study, in both text and tabular form. 
21

Chapter 6 presents a summary of the major findings and conclusions that can be drawn from the results of the study. Implications from the findings and recommendations for further study complete the chapter. 
CHAPTER II

\section{A CAMPUS IN CRISIS TAKES ACTION}

\section{Historical Perspective}

As early as January 15, 1981, Summit Christian College recognized a need to understand why some students remained in college to obtain a degree, while others left prior to graduation. By March of 1981, the institution had organized an Admission/Retention Committee. As noted in committee minutes, "this committee is the official body established and recognized by the faculty to look into the matter of retention of students and therefore should be expected to make proposals and expect some action on those proposals" (Summit Christian College, 1981).

A first task of committee members was to interview departing students in order to discover reasons why they were choosing to leave. A second task was to develop a retention philosophy and strategy. In 1983, it was noted that the college had the same retention rate of $22 \%$ for the previous 2 years. In a paper simply entitled "Retention" compiled by the Retention Committee in 1989, several activities that could improve retention were noted:

1. individual tutoring 


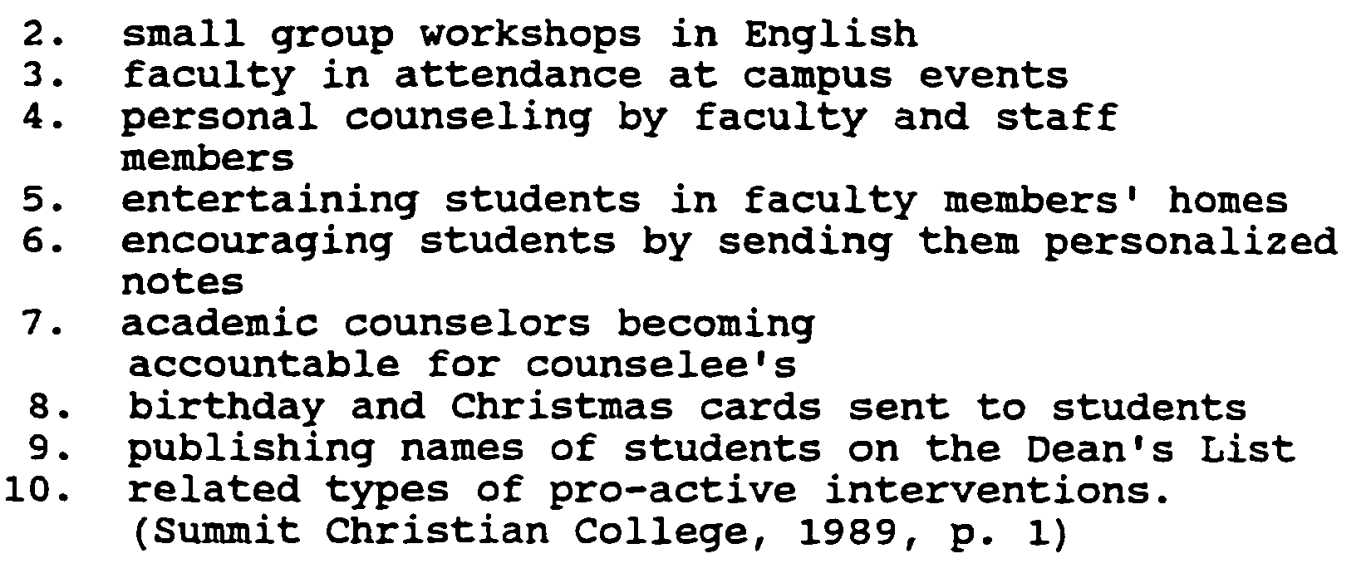

In November 1989, it was noted that attrition would always be a part of higher education. Many factors causing attrition would not change, such as students changing their goals, home situations that demanded their attention, and employment opportunities that became available elsewhere. This same paper noted that $58 \%$ of the entering freshmen in the 1988-89 academic year had taken either vocational or general studies in high school. At the same time, $61 \%$ of this same entering class indicated a need to develop better study skills and habits (Summit Christian College, 1989, p. 2). A Freshman Parent Attitude Inventory indicated that $55 \%$ of the parents did not feel their students had learned how to study in high school.

In 1988, the institution had submitted several proposals to foundations for grant monies to fund a retention study. The assumption was that such a study would provide the institution with the data necessary to identify and implement strategies to meet the needs of academically underprepared students who were typically unsuccessful in completing a baccalaureate degree 
Christian College, 1989, p. 3). The initial focus of the study was on the underprepared student who was admitted to college on probation. It was noted that a 5-year (19841988) study by the registrar found academically underprepared students were typically unsuccessful in completing a baccalaureate degree.

In a 1990 Lilly Endowment Institutional Development Proposal, it was stated that "the Institutional Development program identifies demographic changes as one of the most pervasive forces affecting colleges and universities over the next decade." This proposal quoted a March 1, 1989, Chronicle of Higher Education article stating that the traditional-age student (ages 18-25) population in the Great Lakes region, from which summit Christian college drew most of its students, would decline significantly through 1995 (Summit Christian College, 1990, p. 1).

This same paper noted that it would be important to move toward attracting more non-traditional students to the college. Institutional statistics indicated that approximately $45 \%$ of the current male student population was non-traditional. It was further noted that $33.7 \%$ of the current overall community was non-traditional (summit Christian College, 1990, p. 1). 
Retention of students at summit

Christian college

The scope of the retention problem at summit

Christian College is indicated in Table 2 for the years

1978-1991.

It should be noted that when rumors began to

circulate concerning a possible merger with Taylor

University, a number of students wanted to graduate with a

Summit Christian College degree. This fact may account for

the increased percentage of graduates in 1991, 1992, and

1993.

Table 2

Percentage of Graduates From summit Christian college by Cohort Group 1979-1992

\begin{tabular}{lcc}
\hline $\begin{array}{l}\text { Year } \\
\text { Entered }\end{array}$ & $\begin{array}{c}\text { Graduation } \\
\text { Year }\end{array}$ & $\begin{array}{c}\% \\
\text { Graduating } \\
\text { in } 5 \text { Years }\end{array}$ \\
\hline $1978 / 79$ & 1983 & 28.5 \\
$1979 / 80$ & 1984 & 13.6 \\
$1980 / 81$ & 1985 & 21.2 \\
$1981 / 82$ & 1986 & 26.0 \\
$1982 / 83$ & 1987 & 18.2 \\
$1983 / 84$ & 1988 & 14.1 \\
$1984 / 85$ & 1989 & 25.1 \\
$1985 / 86$ & 1990 & 29.3 \\
$1986 / 87$ & 1991 & 37.0 \\
$1987 / 88$ & 1992 & 32.3 \\
$1988 / 89$ & 1993 & 39.8 \\
$1989 / 90$ & 1994 & 23.2 \\
\hline
\end{tabular}

Note. From Rate of Graduation Projection Chart, Compiled by Academic Dean of Summit Christian College, 1990, p. 1. 
It also should be noted that different methods used by different institutional representatives to calculate the retention percentages may account for some variation in the attrition rates, especially for the years 1990-1994. No matter how the statistics are figured, though, the results seem to be within a few percentage points of each other. with a retention rate of only $22 \%$ for the years 1983 through 1989, it was imperative that summit Christian college search for reasons why students were leaving the college and for new ways of trying to retain them through graduation. In addition, emerging demographics indicated it would be more difficult to recruit new traditional-aged students because of the decline in number of graduating high-school seniors in the Great Lakes Region (see Table 3) (Wilson, 1990, pp. A1 \& A42).

Table 3

Predicted Percentage of Decline in High-School Graduating Seniors (1978-1995), Great Lakes Region 1990

\begin{tabular}{lr}
\hline States & $\%$ \\
\hline Illinois & 16 \\
Indiana & 11 \\
Michigan & 8 \\
Ohio & 9 \\
\hline
\end{tabular}


Based on the information noted above, a grant proposal was drafted to the Eli Lilly Foundation for a study of the issues related to attrition and retention at Summit Christian college. The goal of the study was to enhance the college's services to disadvantaged, at-risk, and non-traditional students. The proposal requested funds to hire Noel/Levitz Centers for Institutional Effectiveness and Innovation, Inc., to conduct a comprehensive retention audit. The grant was funded by Eli Lilly for the 1990-91 academic year.

The focus of the project was to include an audit of marketing and recruiting strategies, as well as retention factors. Its goals were to develop "specific strategic enrollment directions, action recommendations, and policy proposals for future enrollment, development, and retention activities" (Henderson, 1990, p. 4).

\section{Retention Consultation Report for}

Summit Christian College

Michael Hovland, Senior Consultant from Noel/Levitz Centers, Inc., submitted his retention study report to the college administration following an on-site visit to the Summit Christian College campus on December 6-7, 1990. Hovland stated: "The three key elements that promote student success and satisfaction are academic development, personal growth, and social adjustment." He indicated that most of the students felt satisfaction with what was happening academically. The classroom faculty were seen as 
caring and competent with few exceptions (Hovland, 1990, p.

1). Hovland stated:

The goal of a college-wide retention effortis two-fold: a) to build from current strengthsthat represent the best of what Summit Christiancollege is, and b) to assure that as many students as possible are touched by the people, programs, and services that can promote their success and persistence. (Hovland, 1990, p. 1)

He listed the following goals as priorities in the

college's efforts to improve retention:

a. to develop better capabilities to track student persistence patterns

b. to develop a greater sense of community among students, faculty, and staff

c. to place a greater emphasis on getting students started right

d. to work more systematically to develop the basic skills of under-prepared students

e. to better serve the career development needs of all students, and especially undeclared students

f. to integrate off-campus students more fully into student life on campus

g. to provide more college-wide support for chapel and other religious activities

h. to operate with less bureaucratic "red-tape" for students

i. to develop an effective, computerized early warning/early alert system. (Hovland, 1990, p. 2)

Hovland felt these goals could best be accomplished

through the following strategies:

a. a thorough and on-going analysis of student persistence patterns

b. all efforts aimed at promoting a greater sense of community

c. more pre-enrollment assessment of student needs and their readiness for academic success

d. more emphasis on collecting and using important academic and personal information about students

e. more post-enroliment assessment of student satisfaction

f. a greater emphasis on developmental advising and orientation

g. more resources invested in academic support services. (Hovland, 1990, p. 3) 
He suggested that summit Christian college did not have a clear understanding of why students were leaving, a problem that is typical of most institutions of higher education. And, like most institutions, summit Christian College seemed to lack an awareness of the key role of faculty and staff in student retention.

\section{Recommendations for Improving Retention}

Hovland made four specific recommendations to Summit christian college directly related to improving retention rates.

1. explore and develop community-building activities

2. explore and develop spiritual growth through communal worship and fellowship

3. analysis enrollment and persistence patterns

4. develop individual retention programs. (Hovland, 1990, pp. 3-10)

The primary focus of the first recommendation was a recognition of the need to develop a strong sense of community, in which everyone experiences what Hovland called "a good quality of life" (1990, p. 4). He noted, "In a healthy community people enjoy each other's company; they look for reasons to get together frequently, and they have comfortable and convenient places to gather" (1990, p. 4). Problems noted by students, faculty, and staff whom Dr. Hovland interviewed included:
a. less than eager chapel attendance
b. Low participation in campus events
c. "Third Floor Mentality" - "us vs. them" attitude
d. lack of student voice in college policies
e. diversity in the student body resulting in tensions 1. academic
2. socio-economic 
3. geographic
4. religious
5. personal. (Hovland, 1990, p. 4)

Hovland quoted one faculty member as saying, "Some students come here to become prepared, others come to be repaired." He found a significant difference between what students expected from this college and what they found when they got here. For example, many students expected to find a high level of community such as a close-knit family, or in some way to find a "perfect" environment. Many were disillusioned when they found neither was the case. since getting people together is known to be an important element in building community, Hovland suggested six things that could be done:

1. a college-wide coffee-break

2. family recreation nights in the Activities center

3. college-wide major events and activities that demand a real team effort, such as a Christmas concert or some other kind of annual event, symposium, etc.

4. a gathering place or lounge/study area for commuting students

5. more efforts to include a broader cross-section of faculty, students, and staff in clubs and organizations, prayer groups, Christian service activities, etc.

6. using selected administrators and staff to teach credit courses such as Learning Process or noncredit special interest courses. (Hovland, 1990, p. 5)

The focus of his second recommendation was an evaluation of the chapel experience in developing spiritual growth, and what he called "communal worship and fellowship" (Hovland, 1990, p. 6). 
Hovland discovered a general feeling among both students and faculty that chapel did not fulfill all the community-building possibilities they expected. Some students slept in chapel while others read and/or studied. Hovland noted that most people seemed to focus on the fact that chapel was required, while few people indicated any benefits gained from the experience. He recommended the following:

a. strongly encourage all faculty, staff, and administrators to attend chapel every day.

b. consider closing administrative offices during chapel

c. encourage the highest quality and most diverse chapel programming

d. discourage activities and meetings that compete with chapel. (Hovland, 1990, p. 6)

Hovland's third recommendation emphasized the need to analyze enrollment and persistence patterns so the college could determine more accurately who was leaving the institution and why, and who was persisting and why. He said:

To be effective, enrollment management needs to be a data driven process. The schools in the best position to be proactive.. . have the data to answer the following questions:
a. who enrolls and why?
b. who persists and why?
c. who fails and why?
d. who succeeds and why? (Hovland, 1990, p. 7)
To do this type of analysis it is important to

understand academic, personal, and demographic data. He suggested that the institution needed to study at least 2 years of data to begin to understand these trends in attrition and retention. He felt a 2-year study was one of 
the most important factors to consider; this would keep the study cost-effective.

Hovland's final recommendation focused on using the information gathered during the admissions process to develop an individualized retention program to meet the needs of specific students. For example, it would be important to identify students with high-risk factors such as personal and/or financial needs. It would also be important to identify students who might be considered high-risk academically, for whatever reasons. This type of attention, it was hoped, would have a positive effect on the retention of low-risk students as well.

Hovland felt that it was important to identify potential problems before they occurred and to develop individual responses to meet identified needs. He stated, "Many of the best-retaining schools use pre-enrollment data to identify or put up a 'red-flag' for high-need or highrisk students" (Hovland, 1990, p. 9). He made the following observations concerning characteristics generally linked to attrition. Students were considered "high risk" if they:
a. are academically under prepared
b. are undecided about their major and career goals
c. commute rather than live on campus
d. feel a school is too expensive
e. don't get involved in school activities
f. attend part-time rather than full-time
g. come from a great distance
h. have parents and siblings who have not attended a post-secondary institution
i. enter a school with the intention of transferring 
j. do not value the educational philosophy of a particular school. (Hovland, 1990, p. 9)

The concern for retention at summit Christian College has been expressed over the years in a number of studies made by the institution itself and finally culminated in Hovland's study by the Noel/Levitz Center in 1990. A review of statistics from the college revealed, however, that there had been no significant change in the overall retention rate since 1981.

It was the observation of the author of this study that the work of Dr. Hovland was put on the shelf. However, the observation was made by one of the committee members that the college was already doing some of the things Dr. Hovland suggested. It is fair to assume that an institution in survival mode, living from one year to the next, either did not have the resources to implement many of the suggested programs or the energy to focus on another task.

\section{Summary}

The focus in retention efforts has shifted from program development to providing a better learning environment, to finding students who would fit into a particular college setting, and to providing better academic programs.

A brief look at some of the programs developed in the past few years demonstrates the emphasis placed on programmatic solutions to retention. The primary emphasis 
has been on better admissions screening, programs to assist the student's adjustment to college, student services programs to assist in residence-hall living and career exploration, better academic advising, and related processdriven programs.

Based on the work of Tinto (1987), Cash and Bissel (1985), Fischbach (1990), and Kalsbeek (1989), it appears that research in retention to date has not dealt with the relationship between the faculty personality types and student personality types interaction and retention. The effect of this relationship may be especially evident in the small, private christian college where community is often believed to be an important characteristic of the institution.

At the same time, Keirsey and Bates (1984), Beidier (1990), and Cross (1990) suggested that more emphasis needed to be placed on the role of the faculty member in retention. If the faculty member is a person who deeply cares for the student, then effective teaching is more likely to evolve. At least the student will know that he or she is cared for and respected as an individual.

In the 1950s, Isabel Myers rediscovered the work of Carl Jung on personality types. With the help of her mother, Katharine Briggs, she developed the Myers-Briggs Type Indicator (M-BTI) as a tool for identifying sixteen personality types (Keirsey \& Bates, 1984, p. 4). Research using the Please Understand Me (PUM) an adaptation of the 
M-BTI spearheaded by Keirsey and Bates led to a greater awareness of personality types related to communication and leadership styles. Keirsey and Bates (1984) and Kroeger and Thuesen (1988) expanded this concept to look at teaching styles and learning styles based on personality types.

A brief look at the retention studies at summit Christian college over the past 15 to 20 years tended to indicate a typical pattern of assessment, analysis of enrollment and attrition data, and an attempt to design specific programs to deal with a $22 \%$ retention rate. While a great deal of energy was expended, very little change in the retention rate occurred over that period of time. Michael Hovland, a senior consultant with Noel/Levitz, indicated in his report to the administration of Summit Christian College in 1990 that there are three key elements that promote student success and satisfaction: (1) academic development, (2) personal growth, and (3) social adjustment (Hovland, 1990, 9.1). Hovland found that students at sumit christian College were satisfied with the level of caring shown them by the faculty and with the academic competency of their instructors. The general level of satisfaction with the school was considered to be high, based on the students he interviewed.

I would posit that any retention program must deal with the question of interpersonal interaction 
36

between faculty members and students at the basic point of meeting--the classroom. This study focuses on the significance of this relationship in retention at summit Christian College. 
CHAPTER III

\section{LITERATURE REVIEW}

To lay an adequate foundation for the study undertaken, it was necessary to examine the literature in several areas: (1) college-retention studies, (2) programs to improve college retention, (3) teaching styles based on personality type, (4) Jung's theory of personality types, (5) the Myers-Briggs Type Indicator (M-BTI), and (6) learning styles based on the M-BTI.

\section{College-Retention studies}

Several studies emphasize the importance of faculty/student relationships as a method for understanding the concept of faculty/student interactions and their relationship to retention. According to Tinto:

Though we have been able to map out the dimensions of the patterning of rates of departure among the student population generally and have come to associate certain individual attributes with differences in rates of departure, we have only recently begun to scratch the surface of the complex processes of interaction among people within institutions which give rise to those patterns. (Tinto, 1987, p. 36)

Following is an outline of Tinto's Integration

Model.

I. The stage of preparation

a. disassociation from the family

b. disassociation from high school 
c. disassociation from past experiences

II. Transition to college, passage between the old and the new

a. acquisition of new norms and standards

b. appropriation of new behavior patterns

c. personal bonding as a new member of the community

d. establishment of educational goals and a commitment to these goals

III. Incorporation in college, becoming integrated

a. finding membership in social/educational factors of the institution

b. residence life, fraternities/sororities, dorm life

c. student union activities

d. extracurricular programs

e. intramural athletics

f. learning the ropes without outside assistance. (Tinto, 1988, pp. 438-450)

According to Tinto, the attrition process follows

the same pattern only in reverse. He calls this the

"stages of Student Departure" (Tinto, 1988, p. 450).

Referring to Durkheim's theory of suicide, Tinto compares

the social and intellectual forces at work in the

integration of humans into a community with what happens

in a college setting.

It argues that student persistence is very much like the process of social and intellectual integration which characterizes individual membership in human communities generally and the voluntary student departure is not dissimilar from that of suicide from those communities in the sense that both appear to reflect the absence of significant social and intellectual contact between the student and other members of the college community. (Tinto, 1988, p. 447)

Paraphrasing W. Newmann in his Ph.D. dissertation from Syracuse University (1985), Tinto said, "What he discovered was that successful students consistently made use of the metaphor of having successfully made the 
passage to college life and having been helped over the threshold by some nember of the faculty or staff" (Tinto, 1988 , p. 450).

In 1993, Cabrera, Nora, and Castaneda published a paper examining the extent to which the two models, Student Integration Model and the student Attrition Model, can be merged to enhance the understanding of the process that affects a student's decision to persist in college. This study indicates that student persistence in college is the result of a complex set of interactions over time. The two models tend to overlap in terms of courses and academic integration, institutional commitment, and institutional fit and quality. On the other hand, the Student Integration Model appears to suggest that academic integration, social integration, institutional commitment, and goal commitment have the highest level of impact on student persistence. Research on the student Attrition Model emphasizes student intent of purpose, attitudes, institutional fit, and external factors such as family approval of the institutional choice, friends' encouragement to continue in college, attitudes toward finances, and the perception about the opportunity to transfer to other institutions if students choose to withdraw from their present institution.

The research by Cabrera et al. (1993) used a baseline model to identify both theoretical frameworks. The student population for their research was drawn 
from the fall 1988 entering freshman class at a large southern urban institution. The survey yielded 466 useable surveys. Their research used a factorstandardized parameter estimate of 1.000 . The total coefficient of determination for the overall model was 0.644 percent.

From this study of the Tinto Model, Cabrera et al. (1993) developed a third model of student persistence. The effects on student persistence were as follows:

1. Intent to Persist (.485)

2. Grade Point Average (.463)

3. Institutional commitment (.273)

4. Encouragement from Friends and Family (.217)

5. Goal Commitment (.133)

6. Academic Integration (.083)

7. Finance Attitudes (.054)

8. Social Integration $(.046)$.

When the Intent to Persist was explored they discovered that the largest total effects were as follows:

1. Institutional commitment (.562)

2. Encouragement by Friends and Family (.447)

3. Goal Commitment (.274)

4. Academic Integration (.171)

5. Social Integration (.094)

6. Finance Attitudes (.026) (Cabrera et al., 1993, p. 134). 
In summary, Cabrera et al. (1993) suggest that the Tinto model tends to try to understand the complex factors involved in shaping commitments on the part of the student. When the studies of retention and attrition are combined, greater emphasis is given to the socialization and academic experiences of the students. The successful retention program will attempt to combine all of the complex factors mentioned in the combined Retention Model suggested by the Cabrera et al. (1993).

Additional studies seem to emphasize the concern for the quality of interaction between faculty and students as indicated by Tinto. For example, a study of retention at Roberts Wesleyan College, a 4-year liberal arts college in New York state, focused on the development of

an innovative learning center, a freshman seminar, changes in the opening freshman orientation program, hiring a Director of Curriculum and faculty vitality, a faculty growth contract system, and improved oncampus counseling services. (Lenning \& Mohnkern, 1986, abstract)

The program at Roberts Wesleyan College resulted in an immediate decline in the attrition rate of freshmen at the end of the first 6 weeks of classes from $12 \%$ in 1982 , to $1 \%$ in 1984 , and $2 \%$ in 1985 .

Another study by Cash and Bissel (1985, abstract), using Tinto's Model of Attrition on Church-Related Campuses, concluded that integration into the academic program as well as integration into the social affairs of 
the campus was important in determining the quality of any successful retention program. This study demonstrated that the extent and quality of student-to-student interactions and student-to-faculty interaction were important indicators in student retention. Other factors that were seen as having importance in student retention included:

1. The student's family background

2. Individual differences in intellectual and motivational levels

3. Type of pre-college educational experience

4. Students' expectations relative to level of education required to achieve personal goals

5. High-school grade point average

6. The individuals' perception of their own intellectual skills

7. Interaction with their peer group

8. Student-faculty interaction outside the classroom

9. Their participation in extracurricular activities (Cash \& Bissel, 1985, pp. 16-21).

In a study conducted at Illinois central college in 1990, Fischbach reported that students indicated the most important factor in their college success was their relationships with faculty. This result was the same whether it applied to vocational/technical programs or academic programs. 
In looking at pre-enrollment statistics, Fischbach found that several other factors were of significant importance in understanding possible reasons for college success:

1. ACT scores

2. The student's age

3. High-school-class percentile rank (Fischbach, 1990, p. 13).

He further found that students placed a great deal of emphasis on:

1. Family support in dealing with personal factors

2. Student workload

3. Financial stability

4. Availability of transportation. Transportation might be of special significance relating to college survival where there is a rather large percentage of commuter students (Fischbach, 1990, p. 34). The Trails Project at st. Louis University attempted to relate learning style to the Tinto Model of student retention (Kalsbeek, 1989, p. 2). In that project, Kalsbeek attempted to bring learning styles into a conceptual framework of personality characteristics in an academic setting in order to assess their impact on the retention process. The Myers-Briggs Type Indicator, which is based on the conceptual theory of Carl Jung, served as the foundation used in developing a personality profile 
for entering freshmen. These data were stored in a database system along with ACT/SAT scores, high-school grade point averages, demographic data such as gender, race, etc. The database allowed faculty to answer such questions as:

1. What student personality types tend to take specific college majors?

2. How well do different personality types do in certain academic programs?

3. Can some personality types do better in certain majors than might be expected based on their aptitude scores?

4. Can personality types help in predicting the probability of students dropping out of certain majors?

5. Can personality types predict student success more effectively than aptitude scores?

6. Can certain personality types be described as high-risk students?

7. Can personality types indicate career preferences? (Kalsbeek, 1989, p. 2).

Preliminary evidence indicated that there is a direct correlation between personality type and student performance on standardized aptitude measures such as the ACT and the SAT. For example, students with certain personality types appear to do better academically than others in specific curricular areas. Kalsbeek concluded that there is a definite relationship between personality 
type and retention. He further determined that some personality types could be described as "high risk" students (Kalsbeek, 1989, p. 3). There is some indication that the greater the preference for introversion (I), Intuitive (N), and judging ( $J$ ) characteristics, the better the GPA. It would seem that the sensing type does not appear to be a significant factor in retention of students (Kalsbeek, 1989, p. 6).

In some studies there is a definite attempt to relate personality types to learning styles using the $\mathrm{M}-$ BTI. The terms are used interchangeably by some researchers. For example, a study of the relationship between the M-BTI personality types and learning styles by Brownfield (1993) assesses not only the measure of personality types but the way most types learn effectively and its relationship to retention. He states, "The study of learning styles is a relatively new field" (Brownfield, 1993, p. 6). He goes on to say, "Some people learn visually, some learn through listening, and others learn through a combination of both methods. Whatever the particular learning style of a person, identifying and understanding this style can lead to successful and/or improved learning" (p. 6). After a lengthy discussion of the personality types, he concludes with the following statement:

The benefits of knowing a student's learning stylesare numerous. First, through an understanding of his/her learning styles, the student knows more accurately how 
he/she can better process and put new information to use. Second, the teacher will know how each student is most likely interpreting new information and whether or not a particular lesson or project is suitable to each student's learning style. In addition, knowledge of learning styles can help a teacher better understand each student's strong and weak points and can promote better communication in the classroom. (Brownfield, 1993, p. 14)

Another study using the M-BTI to determine how our personality type influences the ability to succeed in college science programs was conducted by Gerald Tharp, professor in the school of biological sciences at the University of Nebraska (1993). He used the following four dichotomous scales $E-I, S-N, T-F$, and $J-P$ to evaluate 146 students in the lecture section of a general biology course.

Around 40 students were preparing for careers in medically related professions or science fields, 35 had not selected a major or career goal, and the rest were in a wide variety of disciplines in the humanities, social studies, education, business, and other fields. (p. 277)

Tharp suggests that "I-J students had significantly higher grades than did the E-P students, which suggests that the $E-I$ and $J-P$ scales of the Myers-Briggs Type Indicator have more influence on achievement in these courses than do the other M-BTI scales." He concludes:

It appears that college science courses and colleges in general are structured so as to favor the learner who is able to work alone, concentrate well, likes to live in a planned, orderly way (I-J type). Yet, the majority of entering freshmen may be of the opposite $E-P$ type. Is it any wonder that 20 to 30 percent of the students entering our large universities drop out during the freshman year. (Tharp, 1993, pp. 277-278) 


\section{Programs to Improve Retention}

In a paper dealing with the drop-out rate in certain schools as compared to the retention rate in other schools, wu (1992) indicates retention/attrition rates are dependent on contextual or organizational factors as opposed to those schools that operate simply at the individual level. He indicated that schools with lower drop-out rates include:

1. learning is a high priority

2. academic achievement is encouraged

3. students are encouraged to enroll in academic classes.

Schools where the drop-out rate is higher tend to:

1. be lacking in quality of the academic program

2. expose students to demoralizing students

3. expose students to teachers with negative attitudes

4. have teachers who consider students to be difficult to motivate.

In a paper presented at the 13 th Annual Freshman Year Experience National Conference (1994) in South Carolina, Mary c. Starke shared the results of college freshmen enrolled in the college Seminar at Ramapo college in New Jersey compared with the freshmen who were not enrolled in the seminar. The seminar course includes unites on:

1. higher education in America 
2. study skills

3. communication and interpersonal skills

4. substance abuse

5. stress management

6. values clarification

7. volunteerism

8. discrimination.

An evaluation of several predictors relating to students remaining in school indicated that those enrolled in the College Seminar:

1. were involved in more campus events

2. belonged to more student organizations

3. felt more comfortable approaching faculty

4. spoke more frequently with faculty outside of class

5. were more familiar with college support services.

The paper indicated that students enrolled in the College seminar tended to bond more to the institution in terms of interpersonal relationships and therefore experienced more benefits in both the academic and personal spheres (Starke, 1994).

Another program designed to meet the needs of first-time college students and to improve retention was developed by John Gardner at the University of South Carolina in 1980. Named University 101, this program had as its major goals: 
1. to help the student obtain a thorough introduction to their particular institution

2. to better understand what the teaching learning process entails

3. to encourage student involvement in extracurricular activities

4. to become aware of student support systems on the campus

5. to develop better self-awareness and self-esteem

6. to provide basic survival skills for the freshman year and beyond. (Gardner Jewler, 1985, p. xii)

Another program developed at Atlantic Christian

College in Wilson, North Carolina, entitled, "The college

Success Program," had as its major goals:

1. to create a sense of community and friendiness

2. to develop a model of effective communication for sending and receiving information

3. to improve student academic skills where needed

4. to get students involved in the activities of the college and in the community

5. to provide an effective student services program

6. to enhance decision making skills

7. to broaden the students' awareness about social and health problems. (Swartzwelder, 1989, pp. 23) (See Appendix B.)

Rutgers University has developed the Gateway Model to assist in student retention. According to Kluepfel, Parelius, and Godfrey (1994), Rutgers has made retention a university-wide program involving faculty from 10 academic departments. The retention rate from the first to the second year is approximately $90 \%$. Each of the departments has developed and offers subject-specific developmental courses and programs with special focus on meeting the needs of students in what have been termed high-risk courses. The purpose for the designation of high-risk courses has been to take away the stigma often associated with labeling students as high risk. 
The Gateway Model offers developmental

introductory courses under positive conditions. These

courses have smaller classes, better student-faculty

interaction, and high-quality instruction. The teachers

who are selected to teach these courses must have a desire to see students succeed and must be motivated to teach

this type of course.

An attempt is made by the instructors to integrate subject-relevant skills into the content of the course, as opposed to teaching the student study skills.

In the area of the humanities an effort is made to design the courses toward a typical liberal arts perspective by teaching writing skills and critical thinking skills. Many of the classes are limited to 15 students to encourage more faculty/student contact. In addition to benefits gained from the faculty contact, the students also profit from nontraditional modes of instruction. "Individual instructors in Gateway Programs are encouraged to act as part of a team of concerned individuals seeking to do what is in the best interest of students" (Kluepfel et al., 1994, p. 24).

A study at Purdue University (Indiana) assessed the impact of the HORIZONS student support Program on participating college freshmen. The program is a part of the freshmen orientation services. Students are involved in two phases: 
1. meeting for 3 hours per week focusing on the cognitive portion of the program

2. meeting for 2 hours per week focusing on the affective needs.

This study compared 47 freshmen in an experimental group in the fall of 1990 with a control group of those students who did not participate. The HORIZONS group retained $85 \%$ of the students through 10 semesters compared to the control group, which retained only $47 \%$. The increase in retention was evaluated by the students to include:

1. belonging to a support network

2. instruction in effective study methods

3. tutoring (Dale, 1995).

Yet another program aimed at improving retention was begun at King College in Bristol, Tennessee, in 1988. Entitled "Strategies for Success," it was designed to help ease the transition and adjustment to college life for incoming students. In this program the goals were:

1. to help the student adjust to college life

2. to help them be stronger academically

3. to sharpen basic study skills and related life skills

4. to become better at listening and memory work

5. to develop time management skills

6 . to be more aware of good health factors

7. to develop a sense of community on the college campus. (Millard, 1988, p. 6)

In this program the Myers-Briggs Type Indicator was used along with the Discover program, a computerized career guidance system designed by the American college 
Testing program. The strategies for success program was intended to focus on the interpersonal relationship between the faculty and student to facilitate better understanding of how the student can succeed in college. The purpose was to help the faculty understand the variety of student personality types represented in their classrooms and then to adjust their relational style to meet the students' needs. At the same time, students were being taught to understand faculty members and their personality types in order to be better prepared to meet the varying academic expectations of their professors (Martin \& Boyce, 1989, p. 1).

\section{Interactive Styles Based on Personality Types}

A survey of approximately 427 journal articles conducted for this study reiterated that most research in the area of student retention has focused on program development and does not deal with faculty/student personality types and retention. However, the works of Myers and Mccaulley (1985), Keirsey and Bates (1984), Kroeger and Thuesen (1988), and O'Connor (1993) focused on teaching/learning styles based on a study of personality types. These four studies also explored the possible impact of teaching/learning styles on attrition rates. A discussion of these studies is presented in the section of this chapter entitled "Summary of Teaching styles." A 
summary of "Learning styles" is also presented later in this chapter.

Keirsey and Bates (1984) concluded: "Well, everybody's different and everybody's ok in their style as is" (p. 166). The particular personality type does not determine effectiveness in the classroom as much as it indicates a preferred style of communication. What seems to be necessary is that faculty members understand the importance of their personality type and how it will affect the learning style of students. By the same token, the learner must grasp the importance of personality types of faculty and adapt to these types in order to learn effectively.

Retention rates for college students should be enhanced by significant relationships between faculty members and students. Most individuals appear to respond to a need to please others. An article by Cross (1990) dealt with "Teaching to Improve Learning." She argues, "If the goals of the 1980 s reforms is the improvement of students' learning, then how something is taught is every bit as important as what is taught" (p. 16).

To better understand the importance of personality types and the interpersonal relationships that are important in student retention, it is necessary to explore theory as it relates to personality types. 


\section{Jung's Theory of Personality Types}

The concept of personality type was developed by Carl Jung in the early 1920 s as an integral part of his personality theory. Jung posited two psychological types, the extravert and the introvert. The extravert tended to think, feel, and act in relation to his subjective feelings toward objects as well as to other people. This type of personality exhibited a positive dependence on the object. On the other hand, the introvert turned inward so that a negative relationship of the subject toward the object was expressed. Thus anyone who is introverted and turns inward thinks, feels, and acts in such a way that clearly demonstrates that the subject of their attention is the chief motivating factor in life (Jung, 1974, pp. $69-73)$

To further clarify these primary personality characteristics, Jung placed thinking, feeling, sensation, and intuition in relationship with extraversion and introversion. For example, to understand the extravert he suggested consideration of extraversion in relationship to thinking styles. He asked himself how thinking style would modify the personality characteristics of the extravert. By the same token, he looked at what impact feeling, sensation, or intuition would have on modifying an extraverted individual's personality. He posited that thinking, feeling, sensation, and intuition would impact the personality characteristics of the introverted person. 
Jung defined thinking in two ways: active and passive. Active thinking was understood to be directed by the individual, while passive thinking was seen to be more intuitive and tended to be regulated by feelings.

He saw feelings as a primary force in life because they tend to define an individual's values, likes, and dislikes. Feelings extend to every part of the consciousness and can directly affect the person's bodily functions. Jung defined feeling in an active and passive sense, just as he did with thinking. Active feelings would involve participation on the part of the individual. Passive feelings would indicate that the person is excited or attracted to a feeling, but does not necessarily act on the feeling.

According to Jung, sensation or sensing was the psychological function of transmitting a physical stimulus to the perceived image of an external object. For example, intuition was defined as the transmission of a perception in an unconscious way. Intuition could be understood as an instinctive awareness of the content as a whole. Individual parts of the content would not be fully understood, but the person could see the whole picture without using intellect, feelings, or sensations as primary characteristics (Jung, 1974, pp. 69-73). 
Myers-Briggs Type Indicator

The idea of personality temperament was overlooked for a number of years by a majority of psychologists. However, in the 1950s, Isabel Myers revived the idea after reading a book by carl Jung on psychological types. Along with her mother, Katherine Briggs, they developed the Myers-Briggs Type Indicator (M-BTI). This test identified 16 different personality patterns. It has been widely used, both in its original form and in adaptations such as the Please Understand Me inventory developed by Keirsey and Bates in 1975.

In the forward to the Myers-Briggs Type Indicator, Elizabeth Briggs Myers said:

The aim of the M-BTI is to identify, from self-report of easily recognized reactions, the basic preferences of people in regard to perception and judgment, so that the effects of each preference, singly and in combination, can be established by research and put to practical use. (Myers \& Mccaulley, 1980, p. 1)

The M-BTI is based on the assumption that an individual's personality type is inborn and will change very little over time. People who understand individual personality types will learn that they need to accept people as they are and should not try to change them. Differences are usually seen as a strength. The assumption is made that the better the individuals understand their own personality traits, the more clearly they can understand others. 
Effective communication occurs best when people understand individual differences and can accept them as valid (Keirsey \& Bates, 1984). The M-BTI can also give some indication of why people find it difficult to communicate with each other. This aspect of the M-BTI can be utilized to understand the personality types of faculty and students especially in relationship to basic communication patterns. Understanding one's personality type makes it possible to deal more effectively with problems, and to communicate effectively with others who have similar as well as different personality types (Myers \& Mccaulley, 1985; Keirsey \& Bates, 1984).

Research by Myers and McCaulley (1985), Keirsey and Bates (1984), and Kroeger and Thuesen (1988) identified the effects of the combination of perception and judgment with sensing and intuition in developing four type combinations. It was posited by the researchers that by knowing an individual's personality type, one could predict communication and behavior patterns. Understanding these four personality types would lead to defining temperament as the blueprint for each person's actions, making it uniquely one's own.

The M-BTI identifies 16 different personality types. A definition of the four basic personality types was given in chapter 1. Table 4 gives a brief description of the 16 personality types and places them in relationship to the SP, SJ, NT, and NF personality groups. 
Table 4

Sixteen Personality Types Identified

Type Description

I. Extraverted Thinking:

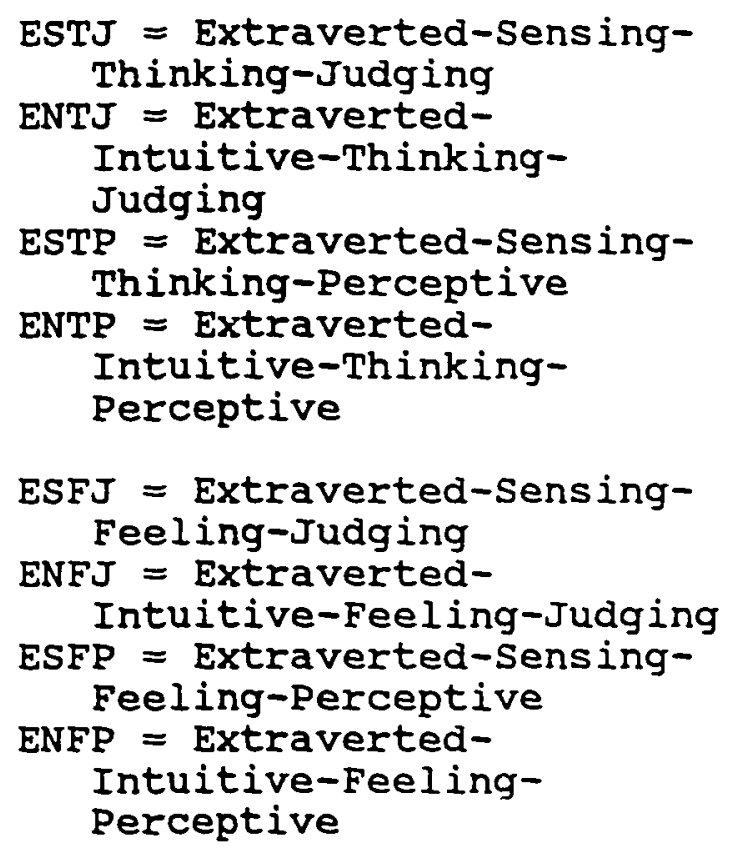
ESFJ = Extraverted-Sensing- Feeling-Judging
ENFJ = Extraverted- Intuitive-Feeling-Judging
ESFP = Extraverted-Sensing- Feeling-Perceptive
ENFP = Extraverted- Intuitive-Feeling- Perceptive

2. Extraverted Feeling

3. Introverted Thinking

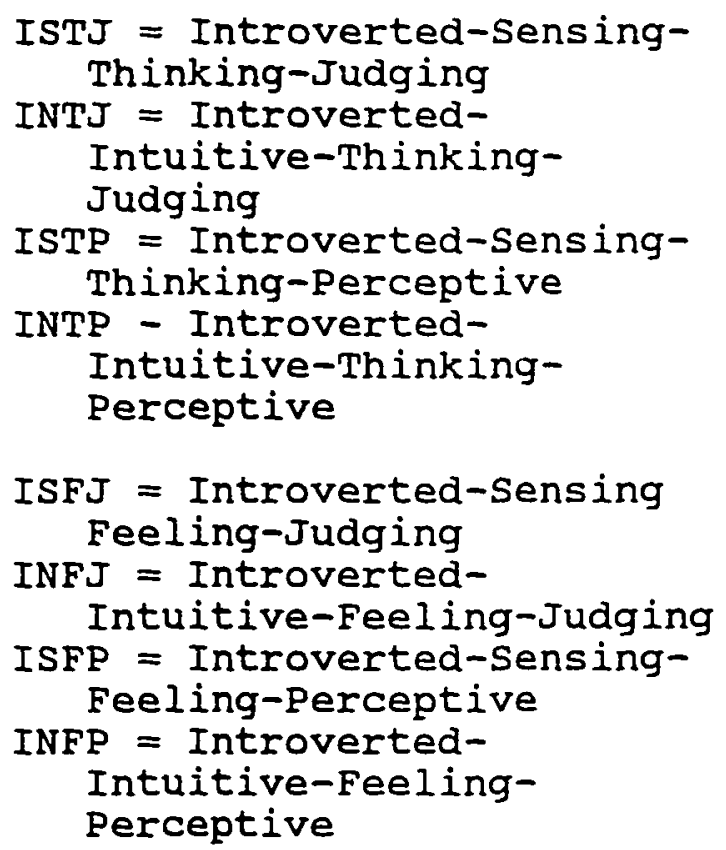




\section{Summary of Teaching styles}

Based on the work by Myers and Mccaulley (1985), Keirsey and Bates (1984), Kroeger and Thuesen (1988), and o'conner (1993), the four basic type characteristics can also be used to identify four basic teaching styles. In the average college classroom setting (including technical and university settings), the four different teaching styles are represented as follows: SP, 6.7\%; SJ, 32.9\%; NT, 27.4\%; and NF, 33.9\% (Myers \& Mccaulley, 1985, p. 134).

Few SP students enter the teaching profession compared to NF students. Approximately $38 \%$ of the total population is comprised of SP and yet only $7.4 \%$ go into college teaching and remain there. At the same time, $12 \%$ of the total population is NF personality type, and $33.9 \%$ enter college teaching as a profession and tend to remain in the field. According to Keirsey and Bates (1984), of all children in school, the SP style is the most misunderstood and most subject to denigration. . . This group is the least represented in institutions of higher learning and tends to have the lowest correlation between academic ability and grade point average. The truth is, unfortunately, that the usual classroom does not fit the unique learning style of the SP child. (p. 122)

This factor is explained in greater detail in the section of this chapter entitled "Understanding Characteristics of Learning Styles."

At the same time, a relatively large number of $\mathrm{NF}$ personality types enter teaching and seem to remain in the 
field for long periods of time. As noted by Keirsey and Bates (1984),

as NFs well know, the pen is mightier than the sword. But the impact of the NF is not limited to the written word. NFs heavily populate the professions of psychiatry, clinical and counseling psychology, the ministry, and teaching. More than any other group NFs can speak and write fluently, often with poetic flair. (p. 61)

In addition the authors said, "Whether a guru of Esalen or a teacher in a more traditional setting the profession of transmitting ideas and attitudes tends to attract NFs" (p. 62). Further they said, the NFs "prefer to work with words, and need and want to be directly or indirectly in communication with people" (p. 63).

These factors are summarized in the next section entitled "Understanding Characteristics of Learning styles."

Based on this brief summary of teaching styles, it would appear that teachers tend to shape their interpersonal relationship expectations and their teaching methods around their particular personality type.

It would logically follow that the personality characteristics found in a student would either complement the preferred teaching style of the faculty member or cause friction between them in the educational process. Therefore, it is also necessary to look at the characteristics of the learner to understand the dynamics of the teaching/learning style and its impact on retention. 
61

Understanding Characteristics of

Learning Styles

Following the pattern established in teaching styles, the M-BTI identify what can be characterized as four learning styles based on personality type. The research of Myers and McCaulley (1985), Keirsey and Bates (1984), and Kroeger and Thuesen (1988) defined these four characteristics: SP, SJ, NT, and NF. On a sample of 18,292 college students enrolled in technical and normal colleges (including universities), $17.9 \%$ of students were SP personality types, $42.2 \%$ were SJ personality types, $17.2 \%$ were NT personality types, and $22.7 \%$ were NF personality types (Myers \& McCaulley, 1985, pp. 46-48). These four personality types that are indicative of learning styles are listed in chapter 1 under the subheading "Definition of Terms" (pp. 10-16).

\section{Summary}

The research related to the $\mathrm{M}-\mathrm{BTI}$ indicates that it is possible to identify personality types that relate to teaching and learning styles with some validity. Such an identification can aid both teachers and students if they are aware of personality types and how they can used to better understand each other and themselves. This awareness might lead to better student-retention rates. 
CHAPTER IV

METHODOLOGY

Type of Research

This is an ex post facto study and seeks to identify if a relationship exists between faculty/student personality types and student attrition.

\section{Population}

The population for this study consisted of two groups: (1) faculty members teaching at summit Christian College in the late summer of 1991; and (2) all entering students in the fall of 1990 and 1991 enrolled in the 2credit-hour orientation course entitled "Learning Process." Since $100 \%$ of the population participated in the data collection, no sampling was undertaken.

\section{Instrumentation}

The Myers-Briggs Type Indicator (M-BTI) and the Please Understand Me (PUM) test are forced-choice tests designed to determine the preference of an individual between two valuable behaviors or attitudes such as extravert or introvert, intuitive or sensing, thinking or feeling, and judging or perceptive (Myers \& Mccaulley, 1985, p. 141). The PUM was selected for use in the 1990 
study because it is an abbreviated form of the M-BTI, is considerably less expensive, and for its ease of administration and scoring. The M-TBI was given to all the faculty members in 1990 and to the freshmen students in the 1991 sample. Because of restricted funds available in 1990 the PUM was used. The PUM seemed to give results similar to the M-BTI and had a comprehensive printout that could be easily understood by the faculty members and the students. The PUM printout could be adapted for the M-BTI giving consistent feedback to both the faculty members and the students regardless of which form they used. According to Wiggins (1989), the M-BTI (from which the PUM is derived) "is an excellent example of a constructoriented test" (p. 538). Each test item is written so that the responses generally reflect two opposing choices. This permits normative scoring.

\section{Administration}

Both tests can be administered by hand on a standard form, or with the grid of a computer-assisted program entitled Please Understand Me, published by Cambridge Career Products (Keirsey \& Bates, 1984). The tests were designed to be self-administered with the instructions clearly given at the beginning of the test. The tests do not have a time limit, but the test taker is encouraged to work as quickly as possible and not linger too long on any one question. 


\section{Development}

The PUM test is an adaptation of the Myers-Briggs Type Indicator, which was developed by Katharine $C$. Briggs, Isabel Briggs Myers, and Mary H. McCaulley (Keirsey \& Bates 1984). The PUM has seldom been used in a research project so that most of the data in this study are explained in terms of the M-BTI. The validity of the results from the PUM are assumed based on the parent test, the M-BTI. The work of Myers and Briggs is based on the personality theory of Carl G. Jung. Writing in the Buros Eighth Mental Measurements Yearbook, Richard Coan (1978, p. 973) said,

The Myers-Briggs Type Indicator represents a major effort to capture the Jungian personality typology in a psychometric instrument. . . The Jungian typology rests on a sophisticated and intricate analysis of the basic modes of variation in human experience. . . . To assess fully an individual's type, we must identify his dominant attitude and his superior and auxiliary functions.

Writing in the Buros Ninth Mental Measurement

Yearbook, Devito said,

The M-BTI is probably the most widely used instrument for non-psychiatric populations in the areas of clinical, counseling, and personality testing. . . . The instrument is intended for normal populations. (1985, p. 1030)

\section{Reliability}

Using a sample from the M-BTI database of 55,971 persons in the general population, 23,240 males and 32,731 females, a split-half correlation was obtained for each variable. Split-half scores are used primarily for use in 
internal consistency reliability calculations (Sax, 1980, pp. 262-264). In this research, items were selected for the two halves by a logical split-half procedure. Each index was split into halves taking all available item statistics into consideration and pairing the items that most resembled each other and correlated most highly (Myers \& McCaulley, 1985, p. 165).

This particular sample of the general population, testing the internal consistency, used the Spearman-Brown formula correction (Myers \& McCaulley, 1985, p. 166). Table 5 tabulates the results of this test. These scores indicate a very high internal consistency.

Table 5

Internal Consistency Derived From Product-Moment Correlations of $X$ and $Y$ continuous scores with spearmanBrown Prophecy Formula correction

\begin{tabular}{lcccc}
\hline Gender & $E-I$ & $S-N$ & $T-F$ & $J-P$ \\
\hline Male & .82 & .87 & .84 & .88 \\
Female & .84 & .86 & .80 & .87 \\
\hline
\end{tabular}

Note: $E-I=$ Extravert-Introvert, $S-N=$ Sensing-Intuitive, $\mathrm{T}-\mathrm{F}=$ Thinking-Feeling, $\mathrm{J}-\mathrm{P}=$ Judging-Perceptive.

Because the PUM has fewer questions, it might not have the same level of internal consistency as the M-BTI. A further reliability estimate was made by using Test-Retest Reliability estimates from Phi Coefficients 
and the Tetrachoric correlations. The sample was drawn from 100 male Brown University freshmen, and 100 female Pembroke College freshmen (and may not be representative of all students in the United states or at Summit Christian College).

For the M-BTI, test-retest reliabilities go beyond the typical computations of correlations for the four continuous scores. The practical questions revolve around the likelihood that on retest a person will come out the same M-BTI type; that is, a person will choose the same pole of all four dichotomous preferences.

Reliabilities in this section include (a) correlations of continuous scores, (b) the proportion of cases assigned the same letter (direction of preference) on retest, and (c) the proportion of cases reporting on retest all four preferences the set (i.e., the same type), three preferences, two preferences, one preference, or no preference the same. (Myers \& Mccaulley, 1985, p. 170)

The author of the internal consistency study indicated that the "Phi coefficients tend to yield low estimates of true values, and Tetractoric coefficients tend to yield high estimates of true values" (Myers \& Mccaulley, 1985, p. 171).

In conclusion, it would appear that test-retest reliabilities do show consistency over time. When a person reports any change in their personality type, it is likely to occur in one preference and then usually only in those scales with the lowest original preference score. (Myers \& Mccaulley, 1985, p. 171)

Table 6 shows the comparison of the freshmen at Brown University and Pembroke college as compared to Table 5 , where a sample of the general population was used. This comparison might not be as valid for the PUM because of 
the fewer number of test items. These scores show a high

level of internal consistency.

Table 6

A Comparison of Internal Consistency of Type Categories Using Estimates from Phi Coefficients and Tetrachoric Correlations, All corrected Using the Spearman-Brown Prophecy Formula

\begin{tabular}{|c|c|c|c|c|c|}
\hline & & $E-I$ & $S-N$ & $T-F$ & $J-P$ \\
\hline \multirow{3}{*}{$\begin{array}{l}\text { Phi Male } \\
\text { rtet Male }\end{array}$} & \multicolumn{2}{|c|}{ Brown University } & \multicolumn{2}{|l|}{ Freshmen } & \multirow{3}{*}{$\begin{array}{l}.58 \\
.76\end{array}$} \\
\hline & $(\underline{n}=100)$ & .55 & .73 & .75 & \\
\hline & $(\underline{n}=100)$ & .74 & .88 & .90 & \\
\hline \multirow{3}{*}{$\begin{array}{l}\text { Phi Female } \\
\text { rtet Female }\end{array}$} & Pembroke & College & Freshmen & & \multirow{3}{*}{$\begin{array}{r}.68 \\
.84\end{array}$} \\
\hline & $(\underline{n}=100)$ & .65 & .64 & .67 & \\
\hline & $(\underline{n}=100)$ & .81 & .83 & .84 & \\
\hline
\end{tabular}

Note: $\quad E-I=$ Extravert-Introvert, $S-N=$ Sensing-Intuitive, $\mathrm{T}-\mathrm{F}=$ Thinking-Feeling, $\mathrm{J}-\mathrm{P}=$ Judging-Perceptive.

\section{Validity}

Writing in the Buros Tenth Mental Measurements

Yearbook, Jerry s. Wiggins said,

For those who would prefer to interpret the M-BTI as a set of four, normally-distributed, bipolar continuous scales, there is a wealth of external validity information presented in the extensive manual that provides a reasonably consistent picture of what the individual scales do and do not measure. (p. 538, 1989)

The manual written by Briggs and Mccaulley compares the M-BTI to such tests as the Adjective Check 
List, the California Psychological Inventory, Comrey Personality Scales, Edwards Personality Preference Survey, Emotions Profile Indices, Eysenck Personality Questionnaires, Maudsley Personality Inventory, FIRO-B, Jungian Type Survey, Minnesota Multiphasic Personality Inventory, Omnibus Personality Inventory, Personality Research Inventory, Stein Self-Description Questionnaire, Bown Self-Report Inventory, Sixteen Personality Factor Questionnaire, State-Trait Anxiety Inventory, study of Values Inventory, Rokeach Dogmatism Scale, Opinion, Attitude, and Interest Scales, Kuder occupational Interest Survey, and the strong-Campbell Interest Inventory. According to Devito (1985), the validity data are presented in such a way as to show the relationship of $M-$ BTI variables to those tests. Myers and Mccaulley presented correlations of the M-BTI with each of these instruments using all of the test dimensions. Devito said:

The correlations between corresponding dimensions are moderately high and statistically significant. Validity data are also presented in the manual showing that self-ratings of type and the assignment made by the instrument have closer correspondence than would be expected by chance. (Devito, 1985, p. 1031)

\section{Procedures}

The Myers-Briggs Trait Inventory (M-BTI) and the Please Understand Me (PUM) tests were administered to the entering freshmen at summit Christian college for the school years 1990 and 1991. The entire faculty (21 
members) was included in taking the M-TBI, while those students (99 students) enrolled in the Learning Process class were tested using the PUM (1990, sample size $=59$ ) and the M-TBI (1991, sample size $=40)$. An effort was made by the examiner to explain the purpose for using the M-BTI and the PUM, as well as to create an atmosphere in which each individual could respond openly and honestly. All of the profiling of the PUM and the M-BTI for this research was done using the Cambridge Career Products computer-assisted program. This entailed transferring the $70 \mathrm{~A}$ and/or $\mathrm{B}$ test scores from the standardized PUM form or the four numbers indicating the personality type from the M-BTI form, on which they were administered, to the computer program. The computer program then ranked the scores, generating a chart showing the percentage for each of the $E$ or $I, S$ or $N, T$ or $F$, and $J$ or $P$ scores. The program was then formatted to provide a printout with sections devoted to personality characteristics, career suggestions, marital relationship suggestions, long-term planning considerations, and the type of person one might consider for marriage.

\section{Nul1 Hypotheses and Analys is Methods}

Three null hypotheses were stated. The second research hypothesis stated in chapter 1 led to two null hypotheses here. 
1. There is no significant relationship between student personality types and the probability of retention. This hypothesis was tested by chi-square analysis.

2. There is no combination of faculty personality types that significantly discriminates between the retention and attrition rates of SJ students. This hypothesis was tested by discriminant analysis. Three analyses were undertaken, each involving two personality types in combination.

3. There is no combination of faculty personality types that significantly discriminates between the retention and attrition rates of NF students. This hypothesis was tested by discriminant analysis. Three analyses were undertaken, each involving two personality types in combination. All hypotheses were tested with $\alpha$ set at .05 .

\section{Limitations}

Evaluating personality types as generated by the Myers-Briggs Trait Indicator and the Please Understand Me test limits the scope of the study to this database only. While some generalizations may be possible, the scope of this study is narrowly defined by a specific goal, attempting to determine if the personality type of faculty members and the personality type of students have any 
71

direct relationship on the retention/attrition rate at Sumit Christian college.

It may be that results of this study could be generalized to other institutions of similar size, mission statement, and with similar retention/attrition problems.

\section{Summary}

This chapter has presented the type of research, the instrumentation used, the reliability of the instruments, the validity of the instruments, the procedures used, and a statement of the hypotheses and methods of analysis. The chapter concludes with a reference to the probable limitations of the study. 
CHAPTER V

RESULTS

\section{Introduction}

The purpose of this study was to determine if a relationship exists between personality types of faculty members and the personality types of students at summit Christian college and to determine if there is any relationship between faculty/student personality types and student retention. The M-BTI and the PUM were the two instruments used in this study.

\section{Distribution of Respondents}

Either the Myers-Briggs Trait Indicator or the Please Understand Me test, an adaptation of the MyersBriggs Type Indicator, was administered to all faculty members at Sumit Christian College in late August 1990 (M-BTI) and all the entering freshmen enrolled in the "Learning Process Class" in the fall of 1990 (PUM) and 1991 (M-BTI) (see Appendix A). There was a 100\% return for both the faculty and all the students.

\section{Faculty Distribution}

Table 7 presents the distribution of faculty respondents based on simple demographic data. A majority 
of the faculty (61.9\%) had been hired within the previous 10 years. It was also a male-dominated group with a 2 to $1 \mathrm{male} /$ female ratio. In 1990 and 1991 there were no minority faculty or staff members at summit Christian College.

Table 7

Demographic Distribution of the Faculty $(N=21)$

Distribution

Rank :

$\begin{array}{lrl}\text { Professor } & 4 & 19.05 \\ \text { Associate Professor } & 13 & 61.90 \\ \text { Assistant Professor } & 4 & 19.05\end{array}$

Gender:

Male

Female

14

7

66.67

33.33

Race :

White

21

100.00

Faculty status:

Tenured

Non-tenured

8

13

38.10

61.90

Summit Christian college

Years of Teaching
1 - 10 years
11 - 19 years
20 years or more

13

2

6
61.90

9.52

28.57 
Table 8 presents this distribution.

The distribution of the personality types of faculty members indicated that only three of the four identified types were present at summit Christian College. There were $52.38 \%$ SJ faculty members, $19.05 \%$ NT faculty members, and $28.57 \%$ NF faculty members.

Table 8

Distribution of Faculty by Personality Types

\begin{tabular}{|c|c|c|c|}
\hline \multirow[b]{2}{*}{ Personality Types } & \multicolumn{2}{|c|}{ Faculty } & \multirow{2}{*}{$\begin{array}{l}\text { Total } \\
\text { Faculty } \\
(\underline{n}=21)\end{array}$} \\
\hline & $\begin{array}{l}\text { Males } \\
(\underline{n}=14)\end{array}$ & $\begin{array}{l}\text { Females } \\
(\underline{n}=7)\end{array}$ & \\
\hline Sensing Perceptive (SP) & 0 & 0 & 0 \\
\hline \multicolumn{4}{|l|}{ Sensing Judging (SJ) } \\
\hline $\begin{array}{l}\text { Professor } \\
\text { Assoc. Professor } \\
\text { Assist. Professor } \\
\text { Total. }\end{array}$ & $\begin{array}{l}2 \\
5 \\
2\end{array}$ & $\begin{array}{l}0 \\
1 \\
1\end{array}$ & $\begin{array}{rr}2 & (9.52 \%) \\
6 & (28.57 \%) \\
3 & (14.29 \%) \\
11 & (52.38 \%)\end{array}$ \\
\hline \multicolumn{4}{|l|}{ Intuitive Thinking (NT) } \\
\hline $\begin{array}{l}\text { Professor } \\
\text { Assoc. Professor } \\
\text { Assist. Professor } \\
\text { Total }\end{array}$ & $\begin{array}{l}0 \\
3 \\
0\end{array}$ & $\begin{array}{l}0 \\
1 \\
0\end{array}$ & $\begin{array}{ll}0 & \\
4 & (19.05 \%) \\
0 & \\
4 & (19.05 \%)\end{array}$ \\
\hline \multicolumn{4}{|l|}{ Intuitive Feeling (NF) } \\
\hline $\begin{array}{l}\text { Professor } \\
\text { Assoc. Professor } \\
\text { Assist. Professor } \\
\text { Total }\end{array}$ & $\begin{array}{l}0 \\
2 \\
1\end{array}$ & $\begin{array}{l}1 \\
2 \\
0\end{array}$ & $\begin{array}{lr}1 & (4.76 \%) \\
4 & (19.05 \%) \\
1 & (4.76 \%) \\
6 & (28.57 \%)\end{array}$ \\
\hline GRAND TOTAL & & & 21 \\
\hline
\end{tabular}


Student Distribution

Table 9 presents the distribution of traditional freshmen students enrolled in "The Learning Process" course. This research was primarily designed to track traditional college freshmen from their matriculation into college through graduation. There were 99 students in the population for this study.

The two predominant personality types among the students are SJ and NF. Because these two types comprised $87.8 \%$ of the total population, I chose to focus the study on these two personality types of students. Because the remaining sample representing the SP and NT personality types was so small they were dropped from further consideration.

Table 9

Distribution of Student Personality Types Tested (in percentages) for Freshmen only, 1990 and 1991 Combined

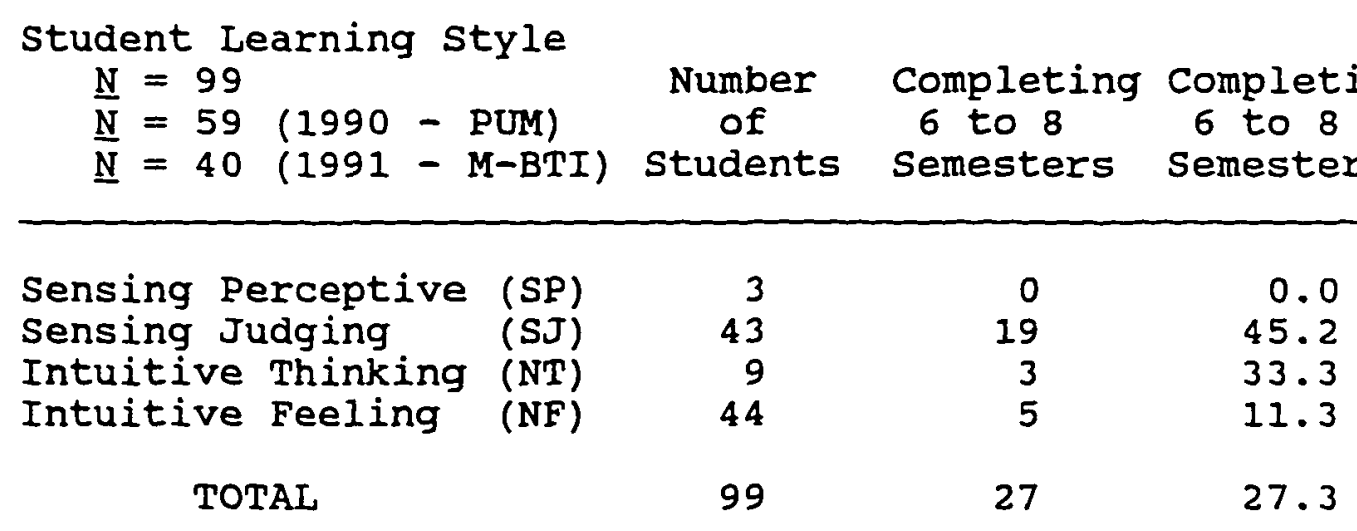


After removing the SP and NT personality types, 34 male and 53 female students remained in this study. Their average ACT score was 20.86. The average SAT verbal score was 415.43 and the average math score was 413.31 . The average high-school grade point average for the group was 2.58. This information would seem to indicate that students in the research project had the intellectual ability to succeed in college.

Therefore it was intriguing to me that $72.7 \%$ of entering freshmen for 1990 and 1991 chose to leave summit Christian college prior to graduation. This statistic corroborates an institutional problem that needs to be addressed. It is consistent with a trend at summit Christian college that has been considered by several methodologies over a period of years from the early 1970 s to the present time. The rate has remained constant at approximately $78 \%$ over that period of time. While there have been some slight changes in the past few years, these changes have been neither significant nor permanent. This study addressed a different dimension of the problem than had been considered in previous attempts to prevent the high attrition rate at summit Christian College. The focus of this study was to determine if there is a relationship between faculty personality types and student personality types that may account, in part, for the attrition problem. 


\section{Testing the Null Hypotheses}

Hypothesis 1: There is no significant

relationship between student personality types and the probability of retention. This hypothesis was tested by chi-square analysis. The contingency table is presented in Table 10. As shown, the value of chi-square is significant. The hypothesis is thus rejected.

There is evidence of a highly significant relationship between Sensing/Judging and Intuitive/Feeling personality types and the probability of retention. A much higher proportion of SJ students (44\%) than those of the other groups completed college. This test does not reveal why SJ students tend to persist in college.

Table 10

Chi-Square Contingency Table Demonstrating Relationship Between Personality Types and Retention Rate for students

\begin{tabular}{|c|c|c|c|c|c|}
\hline $\begin{array}{c}\text { Personality } \\
\text { Type }\end{array}$ & $\begin{array}{l}\text { Completed } \\
\text { Degree }\end{array}$ & $\frac{q}{6}$ & $\begin{array}{l}\text { Did Not } \\
\text { Complete }\end{array}$ & $\%$ & $\begin{array}{l}\text { Total } \\
\text { students }\end{array}$ \\
\hline $\begin{array}{l}\text { Sensing/Juaging } \\
\text { Intuitive/Feeling } \\
\text { other }\end{array}$ & $\begin{array}{r}19 \\
5 \\
3\end{array}$ & $\begin{array}{l}(44.2) \\
11.4) \\
25.0)\end{array}$ & $\begin{array}{r}24 \\
39 \\
9\end{array}$ & $\begin{array}{l}(55.8) \\
(88.6) \\
(75.0)\end{array}$ & $\begin{array}{l}43 \\
44 \\
12\end{array}$ \\
\hline Total & 27 & $(27.3)$ & 72 & $(72.7)$ & 99 \\
\hline
\end{tabular}

$\underline{x}^{2}=12.00 ; \underline{p}<0.005$. 
It should be noted that as the research hypothesis stated in chapter 1 that there is a combination of faculty personality types which significantly discriminates between the retention and attrition groups of students, is now stated as a null hypothesis and is expanded to two statements.

Hypothesis 2: There is no combination of faculty personality types that significantly discriminates between the retention and attrition groups of SJ students. This hypothesis was tested by discriminant analysis. In testing both this hypothesis and the third one, I decided to use, as three separate variables, the proportion of credits a student took with each of SJ, NT, and NF faculty members. This decision was based on the fact that the number of courses taken by each student varied greatly. If all three faculty personality types had figured in a single multivariate analysis, a singular variance/ covariance matrix would have resulted since one variable is linearly dependent on the other two (the sum of the three proportions $=1$ ). Thus, three separate data analyses were undertaken, each involving two of the variables. (Two analyses would have been adequate; but the third one was included as a check for consistency.) Table 11 gives the results of discriminant analysis for the three faculty personality types and SJ students at summit Christian college. The average freshman in 1990 and 1991 was enrolled in 12-15 hours each 
semester during the freshman year. Approximately $80 \%$ of the students were also enrolled in a January term for a total of $31-33$ hours for the first year. The average student would take $54 \%$ of his or her course work from SJ faculty members, $15 \%$ from NT faculty members, and $31 \%$ from NF faculty members. As the output for all three analyses were consistent, the results are included in one table.

Table 11

Discriminant Analysis for SJ, NT, and NF Faculty Members with SJ students

$\begin{array}{lccc}\begin{array}{c}\text { Eigenvalue } \\ +.7036\end{array} & \begin{array}{c}\text { Chi-Square } \\ +13.713\end{array} & \frac{\mathrm{df}}{2} & \begin{array}{c}\mathrm{p} \\ .0011\end{array} \\ \begin{array}{l}\text { Function mean for attrition group } \\ \text { Function mean for retention group }\end{array} & -.576 \\ & +.697 \\ \text { Function weights for SJ faculty } & +.992 \\ \text { Function weights for NT faculty } & -.686 \\ \text { Function weights for NF faculty } & -.378\end{array}$

Table 11 indicates that the null hypothesis is rejected, with $\mathrm{p}-.0011$. The function group means and the faculty type weights in the table indicate that the more credits taken from an sJ faculty, and the fewer credits taken from NT and NF faculty, the more likely the SJ student is to remain in school.

Hypothesis 3: There is no combination of faculty personality types that significantly discriminates between the retention and attrition groups of NF students. 
This hypothesis was tested by discriminant analysis. As with the second hypothesis, three analyses were undertaken, each involving two faculty personality types. For all three analyses involving the three pairs of SJ, NT, and NF faculty members and the NF students, the eigenvalue of 0.959 yielded $x^{2}=1.66$ and $\alpha=.4350$. Thus the null hypothesis is retained. There is no combination of faculty personality types that significantly discriminates between the retention and attrition groups of NF students.

\section{Summary}

With an attrition rate of $72.7 \%$ it is evident from the results of this study that summit Christian college has a significant problem retaining students. Because the college has made many different efforts at retention with little success, this study was undertaken to present another dimension in evaluating the problem.

This chapter presented an analysis of the data generated by this study using the M-BTI and the PUM tests. The three primary personality types of faculty identified at Summit Christian College included $\mathrm{SJ}=52.4 \%, \mathrm{NF}=$ 28.6\%, and $\mathrm{NT}=19.1 \%$. The two primary personality types of students identified were $S J=43.4 \%$ and $N F=44.4 \%$, which accounted for $87.8 \%$ of all students in the study.

A simple analysis of the basedata showed that of the 43 SJ students who entered summit christian college in 
the fall of 1990 and 1991, 24 left the college whereas only 19 were retained. of the $44 \mathrm{NF}$ students who entered in 1990 and 1991, 39 dropped out and only 5 were retained at Summit christian College. Because the sample size is only $5 \mathrm{NF}$ students who were retained, the power of the statistic is too low to demonstrate accurate results. The first hypothesis that there is no relationship between student personality types and the probability of retention was rejected as shown in Table 10 using chisquare analysis. A much higher proportion of SJ students (45\%) than of the other groups persisted until graduation. The second hypothesis that there is no combination of faculty personality types that discriminates between the retention and attrition groups of $S J$ students was rejected as shown in Table 11 using discriminant analysis. SJ students are more likely to remain in school if they are exposed to more SJ faculty members and fewer NT and NF faculty members.

The third hypothesis that there is no combination of faculty personality types that discriminates between the retention and attrition of NF students is retained. There is no significant relationship between faculty personality types and the retention or attrition of NF students. Because the sample size of NF students (5 out of 44) completing their education at summit Christian college was so small, the probability of error is greatly increased signifying that the power of the null hypothesis is low. 


\section{CHAPTER VI}

\section{SUMMARY, FINDINGS, CONCLUSIONS, IMPLICATIONS, AND DISCUSSION FOR FURTHER RESEARCH}

\section{Introduction}

This chapter contains a summary of the purpose, structure, and methodology used in this research, and then presents assumptions about and limitations of the data collected. The major findings are then presented along with conclusions that can be drawn from them. The chapter concludes with implications of the study, recommendations for further research, and reflections.

\section{Purpose}

The purpose of this study was to develop an understanding of the faculty personality types and student personality types at summit christian college and to determine if there is any relationship between faculty/student personality types and student retention. The primary reason the study was undertaken was to search for one or more possible reasons why summit Christian College has had an average attrition rate of $78 \%$ over a period of 14 years, beginning in 1976. Previous attempts to solve the problem had little apparent effect on the 
retention rate. However, none of the previous work had focused on the relationship between faculty/student personality types and retention. The basic question guiding this study was, Is there a relationship between the faculty/student personality types indicated in the Myers-Briggs Type Indicator and the Please Understand Me tests and the retention rate at summit christian college, and, if so, how does this relationship affect retention?

\section{Structure}

The study employed the Myers-Briggs Type Indicator

(M-BTI) and the PIease Understand Me test (PUM), an adaptation of the Myers-Briggs Type Indicator, to generate information from respondents. The M-BTI and the PUM were interpreted to describe personality types of faculty and personality types of students during the academic years of 1990-91 and 1991-92. A copy of the PUM is included in appendix A. The PUM can be scored by a computer-assisted program to produce a 3- to 4-page printout that describes personality characteristics, career options, interpersonal relationships related to the home environment, possible changes that need to be made to adjust to mid-life, and what attracts a particular personality type to other personality types.

The M-BTI and the PUM identify the four basic temperament styles common to all those taking these tests. The four temperaments are Sensing-Perceptive (SP), 
Sensing-Judging (SJ), Intuitive-Thinking (NT), and Intuitive-Feeling (NF). These four temperament types have been associated with different leadership and management styles as well as teaching and learning styles. There is sufficient evidence in the literature to indicate that specific faculty personality types will influence specific student personality types in either a positive or negative manner.

In order to answer the research questions, several hypotheses were formulated. The first hypothesis explored the relationship between student personality types and the probability of retention. The second hypothesis explored the combination of SJ, NT, and/or NF faculty members personality types as they relate to the retention and attrition for SJ students. The third hypothesis explored the combination of faculty SJ, NT, and/or NF faculty members' personality types as they relate to the retention and attrition of NF students.

\section{Methodology}

The M-BTI and the PUM were used to obtain data that address the research questions stated above. This was achieved by administering the Myers-Briggs Type Indicator and the Please Understand Me test, an adaptation of the Myers-Briggs Type Indicator, which was administered to all the full-time teachers in 1990 (M-BTI) and the entering freshmen enrolled in the required Freshmen 
orientation class in both 1990 (PUM) and 1991 (M-BTI).

The full-time faculty members (21) responded with a $100 \%$ return. The test was administered to the students (99) enrolled in the "Learning Process" class, which was required of all entering students in both 1990 (59) and 1991 (40). Because the M-BTI and the PUM were administered in the classroom setting by the author of this study, who was also the primary instructor, there was a $100 \%$ return.

\section{Issues Raised}

Several issues were raised regarding the data generated in this study. First, according to the literature, faculty members' personality type has a direct relationship on the attrition rate of college students. One study cited in the literature review concluded:

It is reasonable to assume that at some stages of learning students do better with a teacher who is a kindred spirit, and at other stages students do better if stretched to understand a mind very different from their own. (Myers \& Mccaulley, 1985, p. 133)

Second, because Summit Christian College had significantly more SJ faculty personality types than all other types combined, the question was raised if these faculty types would have some influence on the retention/attrition rate, especially as it relates to the significant attrition rate of NF students. Third, because it was evident in the literature that the proportion of SJ faculty also seemed to influence 
the retention of $\mathrm{SJ}$ students, the question was examined whether an NF faculty member might have an adverse influence on the retention of NF (as well as the SP and NT types not included in this study) students at summit Christian college.

A fourth, issue suggested that persons with similar faculty/student personality types were more compatible with each other than with persons having other personality types.

A fifth issue suggested that the more balanced the number of SJ, SP, NT, and NF teachers with SJ, SP, NT, and NF students, the better the overall retention rate would be. By virtue of their size, larger universities appear to have a faculty with approximately one-third in each of the primary personality type categories most frequently found at the college and university level, the SJ (32.9\%), NT (27.4\%), and NF (33.9\%) (Myers \& McCaulley, 1985, p. 134). It was assumed that this balance would meet the needs of a larger range of college students than might be found in a specialized type of institution such as summit Christian college.

A sixth issue related to the required 30 credit hours in Bible at Summit Christian College. This specialization is not common to the majority of liberal arts colleges and universities and may significantly alter the results in studies using the MBTI at these institutions. 
A seventh issue raised by the researcher was the possibility that the Bible specialization may account for the large proportion of sJ faculty members who were attracted to teaching in summit Christian college. An eighth issue raised, based on the personality characteristics of the NF student, was that a large number of students were attracted to summit Christian college because of the emphasis placed on training people to enter helping professions, such as pastoral ministry, Christian education, missionary work, and Christian counseling. These professions are more consistent with the personality and learning styles of NF students.

Because the 99 incoming freshmen registered to take the "Learning Process" class in the fall of 1990 and 1991 included only 9 NT students and 3 SP students, I decided to drop these two groups from the statistical analysis. These 12 students would not represent a sufficiently large sample to be significant in determining the personality types using the SPSS-PC statistical program.

\section{Major Findings and Conclusions}

of the 99 students, 43 were found to be $S J$ personality types and 44 were NF personality types. of the 43 SJ students, 19 were retained (45.2\%) through graduation. On the other hand, of $44 \mathrm{NF}$ students, only 5 were retained (11.3\%). Because of the small sample, the 
power of this data is limited significantly. However, this finding still indicates that the NF students were more apt to leave college than SJ students.

There were no SP faculty members at summit

Christian college. In addition, the $12 \mathrm{NT}$ and SP students were deleted from the study because they represented an insignificant number of the total student population being tested.

Since there were more SJ (52.38\%) faculty members represented at summit Christian College than the other personality types, and since the SJ student tended to remain in school longer than the other groups, it might be surmised that faculty with SJ personality types had a positive impact on the retention of SJ students.

\section{Testing the Hypotheses}

Hypothesis \#1 stated that there is no significant relationship between student personality types and the probability of retention. This hypothesis was tested by chi-square analysis. It was found that students with an SJ personality type were more likely to stay in school $(44.2 \%)$, compared to NF students $(11.48)$. Thus, hypothesis \#1 was rejected.

Hypothesis \#2 stated that there is no combination of faculty personality types that significantly discriminates between the retention and attrition groups of SJ students. The discriminant analysis clearly 
demonstrated that there was a significant relationship between faculty personality types and SJ student attrition rate, indicating that $\mathrm{SJ}$ students tend to stay in college when they are taught by SJ faculty members to a greater degree than when taught by faculty members with other teaching styles. Therefore hypothesis \#2 was rejected. Hypothesis 3 stated that there is no combination of faculty personality types that significantly discriminates between the retention and attrition of $\mathrm{NF}$ students. Hypothesis 3 was retained. In the sample reported by this study, there is no combination of faculty personality types that significantly discriminates between retention and attrition of NF students.

\section{Conclusions}

If there is a larger proportion of SJ faculty members and a lower proportion of NT and NF faculty members there is a greater likelihood that SJ students will remain in school.

The Myers-Briggs Type Indicator and the Please Understand Me tests may be tools that can be used to better understand the retention problem at summit Christian college as it relates to how the personality types of faculty correlates with the personality types of the students. 


\section{Discussion}

\section{Convergent Theories Related}

\section{to Attrition}

The growing body of research in the area of retention as seen in this study seems to indicate an awareness of the significance of relationships between students and other students and between students and faculty members as being important reasons why students choose to remain in college.

\section{Divergent Theories Related}

\section{to Retention}

While some of the authors and consultants in the field of student retention often refer to the importance of what they call "fit," or "community," the actual purpose of most retention studies still focuses on programs for personal and academic development of students rather than on faculty/student personality types and other related personality factors.

Such a bias may be an indication of how much easier it is to codify programs, measure their effectiveness, and develop statistical models to analyze the data, as opposed to the more intangible matter of interpersonal relationship factors related to faculty/student personality types and their impact on retention. It is always difficult to study relationships because they tend to be more subjective in nature and change as the student moves through the educational program. 


\section{Implications of the study for} Summit Christian College

Retention is not a simple matter. There are complex issues that need to be considered in implementing an effective retention program. Michael Hovland (1990) considered these complex issues in his study at summit Christian College during the 1989-1990 school year. His report to the faculty needs to be re-evaluated and put into operation. In fact, as indicated earlier, one committee member felt that some of Hovland's suggestions had already been acted upon with some degree of success. One of the most difficult aspects of any retention program revolves around the issue of faculty and staff interaction. The data recorded in chapter 5 may indicate that the more clearly students understand the personality type of the professor, the more likely those students are to be successful and to remain in college. One of the most important tools available to the faculty member is the use of a variety of learning experiences for the different student personality types that exist in any classroom. Perhaps Carl Rogers was correct when he suggested that failure is not the fault of the student, but may be related to the inability of the teacher to facilitate learning. The more understanding the faculty member has of student personality types and their importance to student success in the classroom, and the better the student understands the faculty personality 
type, the more likely the student will achieve success in the classroom. Faculty and students working together for effective learning will equal success in retention.

Not everyone who begins a college program should be expected to obtain a degree, at least not from the institution in which he or she first enrolls. But the student who attends college should experience success. The college or university that can help students feel successful is the institution that will be able to retain the largest number of students.

Higher education is not simply an exercise in intellectual discipline, it is an emotional journey as well. It is imperative that faculty members recognize the feelings of every individual in each class and try to meet those needs. One way to accomplish this is to adapt faculty personality types to particular student personality types, while helping students to adapt their personality type to faculty personality type.

\section{Specific Recommendations for Summit Christian college}

The results of this study suggest some specific issues that need to be addressed by summit Christian College. Many of these recommendations are a combination of concern for faculty personality types as well as student personality types.

The primary concern would be to assist the faculty members in becoming more aware of the importance of 
understanding their personality types and how these characteristics affect the personality types of the students and what effect this may have on student success and retention.

A second factor that might be related to student retention would be to help the faculty members better understand how personality types can have an affect on the choice of a major course of study. To know that students often select a major based on personality characteristics can help in advising students into the right career path (Kroeger \& Thuesen, 1988, pp. 52-61).

The faculty member who is sensitive to the needs of students is more apt to attempt to meet those needs in a caring and understanding way.

At the same time, it would seem to be important to make students aware of their personality types and the effect this awareness can have on their college performance. It appears that the more persons knows about themselves, the more they are able to reach their fullest potential. If a student understands his/her personality type and is able to adapt to the personality type of a specific faculty member, then he or she will be more likely to achieve academic success.

The student who is aware of the significance of faculty/student personality types can better learn how to prepare for each course. He or she will know that an SJ faculty member may expect more homework based on workbooks 
or related kinds of teaching materials, whereas the NF faculty member may be more interested in group participation and individual learning processes.

The "Freshman Orientation Process" (Learning Process) class might be a good place to learn the importance of faculty/student personality types and how they can affect college success. All the freshmen could be given the M-BTI or the PUM tests so they could know what their own personality type is. The students would then have a better understanding of why they learn in a particular manner and understand that their teachers also have a specific personality types that affects how they teach.

Training the faculty members as well as training students could be a part of each fall semester orientation program and could lead to a better retention rate for Summit Christian College as well as other small colleges who might have a similar retention problem.

\section{Limitations and Recommendations for Further study}

There are several factors that may have adversely affected the results of this research project. First, the sample size was relatively small. The findings may have been more valuable if the study had taken place over a longer period of time and included more students.

Additional studies at Summit Christian college should consider more demographic data along with a variety 
of information relative to students' performance in their previous school experiences. Emphasis should be placed on such factors as age, gender, high-school GPA, high-school activities, class rank, college major being considered, clarity of career/life goals expressed, college GPA, specific faculty personality types encountered in the students college classes, extracurricular activities, etc.

\section{Recommendations for Further Research}

The following recommendations arise from the limitations cited above.

The implications of this research would indicate that an important aspect of retention involves the interaction of the faculty with the student in the classroom. Understanding the impact of the individual faculty members personality type and the personality type of the student is certainly one step that needs to be considered in the retention process.

There should be a study of student retention at other colleges with a similar mission statement and purpose to that of summit Christian college. Summit Christian college is a specialized institution with a focus on biblical studies as a key component of obtaining a college degree. It would be useful to know if the issues of faculty/student personality types are similar at these institutions? 
The present study has focused on faculty members' personality traits as an indication of teaching styles and the impact this would have on the retention of students with similar and/or differing personality traits and their learning styles. Some students with personality traits differing from the majority of the faculty members chose to leave the college. If any efforts were made to retain these students, they clearly were not successful. It would be helpful to know what factors would need to have been present for those students to have remained at summit Christian college.

The assumptions made by this study were built on statistical data without any additional information obtained from faculty or students relative to other factors of a more personal nature. Further studies need to focus on personal interviews to broaden understanding of why students left the college as well as why those who stayed chose to complete their degree at summit christian College.

one important recommendation for further research would be to focus on the treatment of students by specific faculty members with differing personality traits. What can be done to develop these skills in all faculty members? Is this something that can be taught or is it an innate characteristic that is not amenable to change through modification of attitudes and behaviors? can an effective retention program be developed on a college 
campus if individuals cannot modify their attitudes and behavior toward students with differing personality types/learning styles?

The opposite side of the issue would be to evaluate the treatment that faculty members with differing personality traits received from students with specific personality types. What do students need to know to become more effective learners in their classes with teachers who have different personality types? Can students learn to adapt their learning styles to become more effective in the classroom? If students learn how to adapt to different instructors, will they tend to remain in college longer?

A larger issue that needs to be addressed is how to define retention and attrition? Is it important for everyone to complete a bachelor's degree once he or she has entered college? Can a person feel successful and attend college for only one or two semesters? Should the college find a way to build into its programs a sense of achievement for the completion of any college courses? Can this be made a valuable experience in the life of the student and recognized as such by the institution? Defining attrition/retention should be one of the most important tasks undertaken by any institution concerned about retaining their students. Is the idea of attrition/retention studies primarily driven by a concern for cost effectiveness? If a particular college is having 
difficulty retaining students, will a retention program solve the real problems, or is an economically driven concern strictly to maintain an institution of higher learning?

Another issue that may need to be considered is the reputation of the institution. Do students tend to persist if they attend a prestigious college regardless of the conflicts they may have with faculty/student personality types? What is the power of suggestion that may relate to getting a job if you graduate from the "right" college as opposed to another school with a lesser reputation? At the same time, it would be important to consider the personality types of students who enroll in institutions with different levels of prestige to see if they are significantly different from those found at summit christian college. Are faculty personality types significantly different in the prestigious colleges? What impact does the faculty/student personality types have on retention in these institutions?

A final recommendation would be to focus on a longitudinal study that would follow the students at Summit Christian college from high school, through college, and into the working world. To understand the effect of attrition on the students themselves, more data is needed than is normally available in a study such as this one. In order to fully understand why students drop out, it would be important to follow up with a study I 
year, 2 years, 5 years later, and perhaps longer to see if the reasons students gave for attrition immediately following their decision were, in fact, the real reasons for their decision to leave college.

With the advent of the computerized admissions system, the records being maintained by the registrar, and the tracking of students that is now being done in the Career Development office, such a study should be possible in the next few years at summit Christian College.

The attrition/retention problem is a perennial one. New directions will need to be sought if we are going to be successful in dealing with this issue in the future. 
A P P E N D I C E S 
APPENDIX A

THE KEIERSEY-BATES TEMPERAMENT SORTER

Reproduced with permission of the copyright owner. Further reproduction prohibited without permission. 


\section{The Kelrsey Temperament Sorter}

1. Al a party do you

(a) interact with many, Including strangers

(b) interact with a low, known to you

PLEASE UNDERSTAND ME

\section{DAVID KEIRSEY \& MARILYN BATES}

TO BE USED PRIMARILY FOR STUDY AND RESEARCH PURPOSES

' TAYIOR.UNIVERSITY FORT WAYNE CAMPUS

YOUR NAME:

AGE : SEX

CLASS RANK:

DATE :

INSTRUCTIONS: circle the responge that geems to be most like you in majority of life

be most like you th dwell too long on any - 1tuations. Do not dwell too long on any response that comes into your mind In the next Per dajs you will be receiving a 3 to 4 page conputer printout detalling aspects of your computer printout detailing aspects of you
2. Are you more

(a) reslistic then speculative

(b) speculative then realistic

3. Is lt worse to

(a) have your "head in the cloudg"

(b) be "in a rut"

4. Are you more impressed by
(a) principles
(b) emotions

5. Are you more drawn toward the
(a) convincing
(b) touching

6. Do you prefor to work
(a) to deedlines
(b) just "whenever"

7. Do you tond to choose

(8) rather carefully

(b) somewhat impulsively

8. At partles do you

(a) stay late, with increasing enersy

(b) leave early, with decreased energy

9. Are you more attracted to (a) sensible people

(b) imaginative people

10. Are you more Interested In
(a) what is actual
(b) what is possible

11. In judging others are you more swayed by

(a) laws than circumstances

(b) circumstances than laws 
12. In appranching others is your incllaatlon to be somowhot
(a) objective
(b) persone

13. Are you more
(a) punctual
(b) loisuraly

14. Doos Il bather you more haviag things
(a) incomploto
(b) comploted

15. In your social groups do you

(a) keep abreast of other's hoppenings

(b) get behind on the news

16. In doing ordinary things are you more likely to
(a) do it the usual way
(b) do it your own way

17. Writers should

(a) "say what they mean and moan what they say"

(b) express things more by use of analogy

18. Which appeals to you moro

(a) consistency of thought

(b) harmonious human relationships

19. Are you more comfortable ia making
(a) logical judgments
(b) value judgments

20. Do you want things

$\begin{array}{ll}\text { (a) settled and decided } & \text { (b) unsellled and undecided }\end{array}$

21. Would you say you are more

(b) serlous and determined (b) easy-going

22. In phoning do you

(a) raroly quostlon that II will all bo :uid

(b) rehearse whal you'll say

23. Facts

(8) "speak for themsel ves"

(b) illustrate principles
24. Are vislonaries

(a) somowhat annoying

(b) rather fascinating

25. Are you more often

(a) a cool-headed person (b) a warm-hearled person

26. Is it worse to be
(a) unjust
(b) merclless

27. Should one usually let events occur

(a) by carelul solection and choice

(b) randomly and by chance

20. Do you feel better about

(a) having purchesed (b) having the option lo buy

29. In company do you
(a) initiale conversation
(b) wail 10 be approached

30. Common sense is

$\begin{array}{ll}\text { (a) rarely questionable } & \text { (b) frequenlly questionable }\end{array}$

31. Children often do not

(a) make themselves useful enough

(b) exercise their lantasy enough

32. In makiag decisions do you feel more comforlable wilh
(a) slenderds
(b) feolings

33. Are you more
(a) firm than gentle
(b) gentle than firm

3.8. Which is more admirable:

(a) the ability to orgenize and be melhodical

b) the ability to adapt and make do

35. Do you put more value on the .
(a) definite
(b) opon-ended 
36. Does new and noa-routine interaction with others

(a) stimulate and energize you

(b) tax your reserves

37. Are you more frequently
(a) a practical sort of person

(b) a fanciful sort of person

38. Are you more likely to

(a) see how others are uselul

(b) see how others see

39. Which is more satisfying:

(a) to discuss an Issue thoroughly

(b) to arrive at agreement on an issue

40. Which rules you more:
(B) your head
(b) your hesrt

11. Are you more comfortable with work that is
(a) contracted
(b) done on a casual basis

42. Do you tend to look for
(a) the orderly
(b) whatever turns up

43. Do you prefer

(a) many friends with brief conlac

(b) a fow friends with more lengthy contact

44. Do you go more by
(a) facts
(b) principles

45. Are you moro Interested in
(a) production and distribution
(b) design and research

46. Which is more of a compliment:

(a) "There is a very logical person."

(b) "There is a very sentimental person."
47. Do you value In yourself more that you are
(a) unwavering
(b) devoted

48. Do you more often prefer the

(a) final and unalterable statement

(b) tentative and preliminary stotement

49. Are you more comfortable
(a) after a decision
(b) belore a decision

50. Do you

(a) speak easily and at length with strangers

(b) lind litllo to say to strangers

51. Are you more likely to trust your
(a) experience
(b) hunch

52. Do you foel

(a) more practical then ingenious

(b) moro ingenious than practica

53. Which person is more to be compllmented; ono of
(a) cloar reason
(b) strong feeling

54. Are you laclined more to be
(a) fair-minded
(b) sympathetic

55. Is if preforablo mostly to

(a) make sure things are arranged

(b) just let things happen

\section{In relationships should most things be}
(a) renegoliable
(b) random and circumstantial

57. When the phone ringe do you
(a) haston lo gel to ll firs!
(b) hope someone else will answer

58. Do you prize more In yourself

(B) a strong sense of reality (b) a vivid imagination 
58. Are you drawn more to
(a) fundemenlals
(b) overtonos

60. Which neeme the grealer orror:
(a) to be too pessionoto
(h) to be too objactive

61. Do you soo yourself as basically
(a) hard-headed
(b) solt-heartod

62. Which altuatlon appeals to you more:

(a) tho struclured and schodulod

(b) the unstructured and unscheduled

63. Are you a person that is more

(a) routinized than whimsical

(b) whimsical than routinized

64. Are you more lnclined to be

$\begin{array}{ll}\text { (a) easy to approsch } & \text { (b) somewhal reserved }\end{array}$

65. In writings do you prefer
(a) the more literal
(b) the moro figurative

68. Is il harder for you to

(a) Identify with others (b) utilize others

67. Which do you wish more for yourself:
(a) clarlty of reason
(b) strength of compassion

68. Which is the greater fault:
(a) boing indiscriminate
(b) being critical

69. Do you prefer the
(a) plenned event
(b) unplanned ovent

70. Do you tond to be more.

(a) deliberate than spontaneous

(b) epontaneous then deliberale 
APPENDIX B

COLLEGE SUCCESS STRATEGIES

Reproduced with permission of the copyright owner. Further reproduction prohibited without permission. 


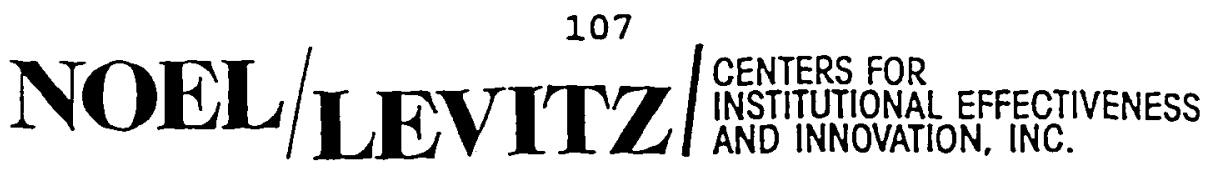 \\ 902 East Second Avenue, Coralville, lowa 52241 \\ (319) $337-4700 \cdot$ FAX (319) 337-5274}

\section{Retention Consultation for Summit Christian College}

The following report summarizes observations and recommendations concerning student retention at Summit Christian College.

Information for this report was gathered from written materials and reports supplied by Summit Christian College and from observations made during a site visit to the school December 6-7, 1990 by Michael Hovland, Senior Consultant from Noel/Levitz Centers, Inc.

\section{Executive Summary}

The three key elements that promote student success and satisfaction are academic development, personal growth, and social adjustment. I feel it is fair to say that in the past Summit Christian has focused more energy and resources on the academic program than it has on the personal growth and social adjustment of students, although I see that changing now with an increasing emphasis on student services. For the most part, the students I talked with seem pleased with what is happening in the classroom. They find the faculty, with a few exceptions, to be caring and competent and interested in their academic development. The students are less satisfied with the opportunities they have at Summit Christian to grow and develop in other areas.

With a relatively strong academic program in place, I feel that Summit Christian will make the most impact in improving retention by focusing on issues of quality of life and community. In addition, retention can be improved by increased attention to academic advising, academic support services, career development, and other aspects of student growth and development.

The goal of a college-wide retention effort is two-fold: a) to build from current strengths that represent the best of what Summit Christian College is, and b) to assure that as mainy students as possible are touched by the people, programs, and services that can promote their success and persistence. This would mean, for example, moving from a system of informal faculty referrals through the Student Development Office to a more formalized and comprehensive early warning/early alert network, or moving from a tutorial program based on some promotion, some referral, and some word-of-mouth advertising to a more intrusively delivered service.

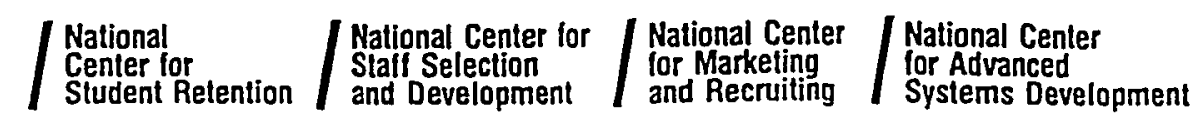


There is widespread agreement among students, faculty and administrators that most faculty and staff project a sincere interest and caring attitude toward students at Summit Christian College. Further, there is widespread agreement that the college offers rigorous and demanding academic and vocational programs, more difficult than many students expect.

In fact the issue of student expectations is in many ways the central retention issue at Summit Christian. This includes both academic and non-academic expectations. In response to my question, "How is Summit Christian College different from what you expected?" most students I spoke with responded that the school was more difficult and demanding than they thought it would be. I am sure this is a sentiment shared by many of their peers. Coupled with the fact that many students enroll with poor academic skills and poor motivation, the fact that the school is more demanding than many students expect suggests the crucial importance of orientation and academic support services.

Also, when asked how the school is different from what they expected, many students say that the college is not the community or family they anticipated. It is clearly the case that expectations are inextricably tied to retention. Whenever there is a gap between what students find and what they expect to find, attrition can and will result. This is a central retention issue at Summit Christian.

I see the following goals as priorities in the College's efforts to improve retention:

a. to develop better capabilities to track student persistence patterns

b. to develop a greater sense of community. among students, faculty, and staff

c. to place a greater emphasis on getting students started right

d. to more systematically work to develop the basic skills of underprepared students

e. to better serve the career development needs of all students, and especially undeclared students

f. to integrate off-campus students more fully into student life on campus

g. to provide more college-wide support for chapel and other religious activities

h. to operate with less bureaucratic "red-tape" for students

i. to develop an effective, computerized early warning/early alert system. 
These goals can best be accomplished through the following:

a. a thorough and on-going analysis of student persistence patterns

b. all efforts aimed at promoting a greater sense of community

c. more pre-enrollment assessment of student needs and their readiness for academic success

d. more emphasis on collecting and using important academic and personal information about students

e. more post-enrollment assessment of student satisfaction

f. a greater emphasis on developmental advising and orientation

g. more resources invested in academic support services.

The goals and approaches listed above are discussed more fully in the report.

Retention is a data-driven process. As is the case with most other colleges, Summit Christian College does not at present have a very good sense of who is dropping out of the programs, when they are dropping out, and why.

These questions must be answered thoroughly before the school can develop retention strategies to attack particular problems.

The general consensus among faculty and administrators is that many of the students who drop out are having academic difficulties and/or motivational and personal problems and drop out fairly early in the program. However, there needs to be a thorough study of persistence patterns to determine the exact cause-and-effect relationships between student characteristics and dropout behavior.

Above all Summit Christian needs a campus-wide commitment to improve retention. A serious commitment will necessarily involve reallocating resources and changing long-held attitudes among many faculty and staff. These are difficult and sometimes painful processes, but well worth the effort in terms of an improved quality of life for everyone in the Summit Christian community.

The College Community

Recommendation \#1:

Explore and develop community-building activities at Summit Christian College.

Discussing the college "community" is difficult. It is a very subjective topic and one that is not easy to address with concrete recommendations.

However, I want to begin the report with a discussion of community because 
it is a very important "umbrella topic" which has implications for many of the following recommendations.

The degree to which a college exhibits a sense of community is often a good measure of its emotional and spiritual health. A healthy institution with a strong sense of community attempts to provide a good quality of life for everyone who studies, works, or teaches there. Community-oriented institutions are committed to the growth and development of all students, faculty, and staff. Employees describe a healthy community as a good place to work. In a healthy community everyone feels part of a shared and important enterprise; the institution's mission statement is precise and unequivocal enough to guide the day-to-day activities of all employees. In a healthy community people enjoy each other's company; they look for reasons to get together frequently, and they have comfortable and convenient places to gather.

There is a widely shared belief among many students, faculty, and staff that Summit Christian lacks a real sense of community. People talk about Summit Christian as a collection of caring individuals, but still they don't see a community. People generally talk about the lack of community in terms that are important to them. Some cite less than eager chapel attendance among students, faculty, and staff. Some cite low student and faculty participation in campus events. Some talk about the diminishing but still evident effects of a "Third Floor Mentality," a certain "us vs. them" attitude. Some talk about students not having enough of a real voice in college policies. Students and the faculty say that they have no good places to gather to relax and enjoy each other's company. Many talk about the great diversity in the student body and the resulting tensions between students who have very different backgrounds in academic, socio-economic, geographic, religious, and personal terms. As one faculty member put it during my visit: some students come here to become prepared, others come to be repaired.

There is a connection between community and retention at Summit Christian because many students enroll at the college expecting to find a strong sense of community. Community is one of the qualities for which they are paying a lot of money. In the minds of many students there is a great difference between their expectations and the reality of what they find. Some on campus would say that many students come with unrealistically high expectations of the level of community at the college; they come expecting it to be a close-knit family, or to be perfect, and it does not always appear to be so.

In fairness I should point out that Summit Christian is under the influence of some factors that do not promote community, such as the large percentage of married and commuting students, and the great diversity of the student body. 
And this diversity may continue to expand if and when the college develops a stronger evening and weekend program.

\section{Approaches to Building Community:}

There are many possible approaches to building community. As I indicated above, an important element of community is simply getting people together, something which requires little more than a place and an occasion. Here are some suggestions:

a. a college-wide "coffee-break" (if chapel were earlier, for example)

b. family recreation nights in the recreation building

d. college-wide major events and activities that demand a real team effort, such things as a Christmas concert, or some other kind of annual event, symposium, etc.

f. a gathering place or lounge/study area for commuting students

g. more efforts to include a broader cross-section of faculty, students, and staff in clubs and organizations, prayer groups, Christian service activities, etc.

h. using selected administrators and staff to teach credit courses such as Learning Process or non-credit special interest courses.

Over the last decade many schools have also worked very hard to make the residence halls better living and learning environments, rather than simply dormitories where students sleep. Programming through the residence halls is often one of the most successful ways to promote student growth and development. It is also one of the best vehicles for building community between faculty and students by setting up occasions for faculty to interact with students in the residence halls.

\section{Retention and Community-Building:}

I bring up the subject of community because I feel strongly that the strategies that improve retention are often the same as those that improve the quality of life for each member of the educational community. Improved retention of students should also lead to happier and more productive faculty and staff. In this respect retention is a quality-of-life indicator, a measure of institutional performance. This is why a concerted retention effort can often be such a great catalyst for both student and institutional growth. If Summit Christian undertakes a serious effort to improve retention, the College should also see some definite improvements in its overall sense of community. 
Spiritual Life, Religious Activities, and Community-Building

Recommendation \#2:

As part of a broader review of community-life issues, the College should evaluate chapel to determine to what extent it promotes spiritual growth and communal worship and fellowship.

\section{Discussion}

Judging from many comments I heard from students, faculty, and administrators, it seems that chapel does not fulfill all the communitybuilding possibilities it might. I asked the two groups of students I talked with whether or not students would attend chapel if it weren't required. The general response was "no, they probably wouldn't." People told me about students who sometimes sleep or study at chapel. At the same time, I should add that many people indicated that chapel had improved the past few years, and several were excited about the new Spring format for Friday chapel.

If the college decides that it wants to put a greater emphasis on spiritual growth and campus community-building through chapel, I would then recommend the following:

a. strongly encourage all faculty, staff, and administrators to attend chapel every day

b. consider closing administrative offices during chapel

c. encourage the highest quality and most diverse chapel programming

d. discourage activities and meetings that compete with chapel.

What came through most clearly to me in my discussions was only the fact that chapel is required. Few people mentioned anything to me about what chapel is like, why they enjoy going, or anything about its advantages and benefits. In the first place, the requirement to attend three of four chapels a week is quite minimal. At many church colleges chapel is held every day. At Luther College where I went to school, daily chapel is still very well attended by large numbers of students, faculty, and staff. It isn't required, but it is a community event which many genuinely look forward to and for which, during that half hour, the college virtually shuts down.

The fact that chapel is required should not be the focus. Rather, the focus should be on what can be done to make chapel an enjoyable and rewarding experience so that all members of the Summit Christian community want to attend. The problem:comes when particular rules and regulations become more important than the benefits and advantages that the rules are trying to promote. They undermine a sense of community and mutual cooperation. 
For these and other requirements, you should strive to provide students with a statement of benefits and objectives. This should be your emphasis when you orient students and parents about what to expect at Summit Christian. And, above all, Summit Christian should continually ask itself how it could improve in each of the areas so that the rules will no longer be necessary.

\section{Tracking and Analyzirig Persistence Pattems}

\section{Recommendation \#3:}

Begin to systematically analyze enrollment and persistence patterns so that the College is able to draw composite profiles of who leaves the College and who persists.

\section{Discussion:}

The most obvious and immediate enrollment management need is to develop an on-line capability to track the persistence patterns of individual students, and, thus, to be able to produce cohort retention studies. To be effective, enrollment management needs to be a data-driven process. The schools in the best position to be proactive rather than reactive in their enrollment management efforts have the data to answer the following questions:

a. who enrolls and why?

b. who persists and why?

c. who fails and why?

d. who succeeds and why?

It is very important to track the progress of students from the recruitment stage through graduation. The school should analyze at least two recent classes according to most or many of the following characteristics:
1. High School.GPA
2. College GPA
3. Transfer GPA
4. Sex
5. Age
6. Ethnic background
7. Hometown (size and location)
8. Distance of home to campus
9. Academic program
10. Housing (commuter vs. resident)
11. Undecided vs. declared 
12. Date of application; date application completed

13. Grades in key high school core courses

14. Attendance at orientation

15. Grades in key first-semester courses

16. Time of dropout

17. Transfer status vs. first-time

18. Involvement in activities

19. Placement tests

20. Enrollment pattërns: i.e., stop-in, stop-out

21. Financial aid

22 Advisor

23. Religious preference

24. Marital status

These profile analyses will provide valuable academic, personal, and demographic data from which to draw conclusions about retention. When research, intuition, and common sense are all applied to analyzing the characteristics of various groups of students, the school would have a good sense of the intervention strategies necessary to improve the retention of these group.

Perhaps the most overriding reason for basing retention initiatives on careful tracking is cost-effectiveness. Few schools have the time, the people, or the resources necessary to meet the diverse needs of all segments of their student bodies. This is especially true of Summit Christian at the present time.

\section{Collecting and Disseminating Student Information}

Retention is also a data-driven process with regard to how information about students is used to promote the retention of individual students. Student information is very useful in identifying both high-need (personal, academic, and financial need) and high-risk students. It is also useful in promoting the retention of lower-risk students.

\section{Recommendation \#4:}

Use the information gathered throughout the admissions process to design specific retention strategies for individual students. Gather the information and be sure it is disseminated to those in the best position to promote retention. 


\section{Discussion}

Gathering and disseminating student information is part of a larger process that we call pre-enrollment assessment. This includes personal and academic information as well as a variety of assessment tools including course placement examinations. The goal of pre-enrollment assessment is to identify potential problems before they occur and to promote an individual response to student needs.

Throughout the admissions process, the school gathers a great deal of personal and academic information about students. Many of the bestretaining schools use pre-enrollment data to identify or put up a "red flag" for high-need or high-risk students. Obviously, this process is made easier by a school's efforts to determine their specific positive and negative retention characteristics. For the present discussion I will focus on several of the student characteristics which affect retention at most institutions.

The following student characteristics are generally linked to attrition:

a. Students who are academically underprepared

b. Students who are undecided about their major and career goals

c. Students who commute rather than live on campus

d. Students who feel a school is too expensive

e. Students who don't get involved in school activities

f. Students who attend part-time rather than full-time

g. Students who come from a great distance

h. Students whose parents and siblings have not attended a postsecondary institution

i. Students who enter a school with the intention to transfer

j. Students who do not value the educational philosophy of a particular school.

It would not be unreasonable to say that Summit Christian enrolls a number of students with one or more of these characteristics. In a pre-enrollment assessment process, the Admisșions Office would identify students, when possible, who share one or more of these attrition characteristics (which have been validated by the tracking discussed under recommendation \#3 above), and these students would be targeted for some type of special intervention. The assessment information would then be passed on to a student's advisor, a counselor, a faculty member or program director, or any others who are in a good position to anticipate problems and positively affect the well-being of a student.

I understand that the Student Development Office is being used to coordinate a number of retention-related activities with individual students such as faculty referrals of students who have academic or personal problems. This is 
a good start, and should provide the basic framework around which to design a more formal early warning/early alert network.

Pre-enrollment assessment also comprises other more formal assessment procedures including assessment in such skills areas as writing and math, and assessment in more subjective areas such as motivation, attitude toward educators, etc. Summit Christian is somewhat handicapped in this regard because of the small percentage of entering students who have taken either the ACT or SAT.

I should mention, too, that post-enrollment assessment is equally important from a retention standpoint as a way of assessing the quality of student/institution interaction. The ACT Student Opinion Survey (SOS) is a very good tool with which to identify performance gaps and to confirm more subjective impressions of retention problems. In addition, the SOS results are nationally normed to: allow institutions to compare their performance with that of similar institutions.

I don't want to suggest that it is necessarily an easy process to devise a system in which pre-enrollment and post-enrollment information is transferred back-and-forth between admissions, student services, and academic advisors, especially as academic advising is currently set up at the College. But it is possible to do, and it is often the backbone of retention efforts at many institutions.

I would suggest that the College may want to consider using the ActionTrack retention software developed by Noel/Levitz Centers. ActionTrack is a stateof-the-art retention software which provides a computerized early-warning, tracking, and referral system. The retention software is very efficient and cost-effective in an environment in which existing support networks are not fully developed.

Finally, I would encourage the College to implement a means of regularly talking to and listening to students. I would specifically suggest periodic focus group meetings with students similar to what we do during our consultations. Students appreciate your attention and interest, and you'll find out a great deal through such discussions about how students view the College. 
Admissions

Recommendation \#5:

Review the existing admissions standards and consider moving toward a more restrictive policy.

\section{Discussion:}

I understand that over the past several years Summit Christian has operated as an open admissions institution. I also understand that many at the institution have felt this was necessary because of the increasing pressures to fill an incoming class. However, I have some concerns that over time such a policy can have negative consequences for both recruitment and retention that can offset the limited advantages of admitting a few extra students.

Another admissions topic related to retention that needs some attention concerns the intentions enrolling students have of graduating from Summit Christian. Many people feel that a number of students come to Summit with the intention of transferring to other institutions such as Taylor University. Or they may enroll with the intention of taking a year of Bible before transferring to another four-year college or university to pursue an entirely different academic or professional program. It is generally helpful to students, faculty, and staff if these intentions are clear from the beginning. Thus, I would suggest that an item be added to the admissions application to assess a student's intent upon enrolling. Are they planning to get a degree from SCC, do they intend to take courses for personal or professional improvement with no intention of getting a degree anywhere, or do they plan to transfer to another school?

\section{Getting Students Started Right}

The retention literature suggests strongly that one of the most important aspects of retention is "getting students started right." This is accomplished by focusing on students' academic, social, and personal development. If students feel as if they are succeeding in the classroom and growing personally and socially they are more likely to stay enrolled. I like to refer to this as the "velcro approach." The more points of connection a student makes with an institution and with its people-students, faculty, staff, and administrators-the more likely the student is to stay enrolled.

The retention literature suggests further that what happens during a student's first term-many even say the first six weeks-will determine whether a student decides to stay or leave. 
During these first few weeks students determine how their expectations of the school fit the reality of what they find at the school (or what they think they find at the school). How does an institution take an active role in getting students started right? One of the most effective approaches is through the use of an extended orientation course.

\section{Recommendation \#6:}

Consider developing the current Learning Process Course into a fullblown extended orientation course, in particular to allow for the inclusion of more developmental advising activities such as career planning.

\section{Discussion:}

It seems that many of the retention issues at the College are, at heart, issues of orientation in the broadest sense. Students need to be effectively oriented to their programs, their future jobs and professions, to Summit Christian College, to Fort Wayne, to the varying demands and expectations of each level of programs, and to themselves--their own interests, abilities, and skills, and how these relate to their success in the programs and in the professions.

Hundreds of schools around the country have discovered that extended orientation courses (usually a term-long, 1-2 credit course) are the most effective ways to address a variety of retention issues and problems. These schools recognize that effective orientation is not something that can be accomplished in a few days before school starts. Extended orientation is really at the heart of getting students started right.

There is extensive objective evidence to suggest that extended orientation courses increase retention, improve academic performance (including grade point average, communication skills, units completed, academic dismissals, study habits and attitudes, and relations with faculty), and increase knowledge and use of student services. In addition, evidence suggests that these courses positively affect personality development of students by lowering apprehension, encouraging social involvement and responsiveness, and helping them become more self-disciplined.

An extended orientation course for all new students is perhaps the best approach to get at some of the misperceptions and misconceptions most entering college students share. It is clear that many students do not necessarily enroll with.much understanding of what people in certain careers do, what skills are necessary to work in a given field, or how the school training relates to the career field. According to people I talked with, many students at Summit Christian lack direction; they don't know why they're 
there. These gaps in perceptions or expectations can obviously contribute to retention problems, and they can often be effectively addressed through an extended orientation course.

It seems that a version 'of an extended orientation course, perhaps an expansion of the current Learning Process Course, would be the best approach to getting at some of the first-semester problems outlined above. I heard few if any positive comments from students about the current course. They expect to get very little from it, particularly the better prepared students. This would seem like a good time to review the content and purpose of the course with an eye to making it into a course that will provide a more effective orientation to the college.

\section{Integrating Off-Campus Students}

\section{Recommendation \#7:}

Explore ways to ibetter integrate the full time off-campus students, especially new frestimen, into student organizations and campus life.

\section{Discussion:}

Getting started right is particularly important for new students who live offcampus. Off-campus students generally are much less likely to make the kinds of interpersonal and institutional connections that are crucial to retention. The extended orientation course provides some opportunities for off-campus students to develop out-of-class relationships with both students and faculty. In addition, Summit Christian could also consider other approaches, such as making every new off-campus traditional-age freshman a "memiber" of a residence hall floor group, or developing an on-campus

"host" program for every new off-campus student.

$i:$

Meeting the Needs of Under-prepared Students

\section{Recommendation \#8:}

Make an institutional effort to meet the needs of the many academically underprepared and undecided students who enroll at Summit Christian College. 


\section{Discussion:}

Almost everyone I talked with at Summit Christian College is in agreement that the College enrolls many students who lack the basic skills necessary to complete the kind of demanding programs that Summit Christian College offers. In a recent semester, 135 out of 335 students were on Academic Alert, while only 85 were on the Honor Roll. From what I understand, over $50 \%$ of the entering male students have taken a high school curriculum other than college prep.

The lack of basic skills can show up in a variety of ways and in a variety of courses: poor functional math skills, the inability to answer essay questions, poor note-taking, lack of organizational skills, lack of abstract and relational skills, lack of problem-solving skills, poor reading comprehension, and poor written communication.

The key is to get underprepared students connected early on to the academic support services that can promote their success. Like many schools, Summit Christian College may find that it must be very creative and aggressive in its efforts to reach these students.

This is not a situation unique to Summit Christian College; hundreds of schools around the country are in the same position. The problem is not being an open-door institution. There are many excellent and effective opendoor institutions. The important thing is what happens to students after they enroll: do they find themselves in a sink or swim situation or one in which they are given a reasonable chance to succeed? The retention tracking you do will determine accurately the connection between academic preparation and Summit Christian College performance.

\section{Administrative Bureaucracy and "Red-Tape"}

There is a widely held belief among many of the groups I talked with that the college has more bureaucracy and "red-tape" than a college its size should have.

\section{Recommendation \#9:}

Identify the offices and procedures that irritate staff and students most, and determine more user-friendly approaches to the existing problems. 


\section{Discussion:}

The issue of bureaucracy is problematic because students at most institutions complain about the same things. However, I heard enough complaints at Summit Christian from students as well as faculty and administrators to make me believe that there is room for improvement in this area. I don't know to what extent the problems involve people or systems, or both. Of particular concern to many is what they perceive to be duplicated efforts and procedures at both pre-registration and regular registration.

The issue of excessive bureaucracy is related directly, I feel, to the issue of expectations discussed above. Problems with "red-tape" may not be bad in an absolute sense, but may be bad in relation to what students expect to find at Summit Christian, and what they feel they are paying for. 
Lilly Endowment:

Institutional Development Proposal, 1990

Proposal Summary:

Reauthorized in November 1988, the Institutional Development program, identifies demographic changes as one of "the most pervasive forces affecting colleges and universities over the next decade." In fact, the Chronicle of Higher Education (3/1/1989), indicates that traditional student populations for the great lakes region (which the College serves) will decline significantly by 1995 (Indiana--11\%, Illinois--16\%, Michigan--8\%, Ohio--9\%). While the college gives serious attention to competitive marketing to traditional students, the 1988 ACT Entering Student Survey (Exhibit I, excerpt) evidences that $45 \%$ of the male student population is nontraditional. Further, $33.7 \%$ of the current community is nontraditional in character. What is more, the college, though it chooses not to receive direct federal assistance, believes that it would qualify for Title III funds: a significant majority of its enrollees would be identified as "first generation" college students. These students are identified as disadvantaged by the government.

Sumit Christian College respectfully requests $\$ 8250$ for the $1990-91$ academic year to address issues in attrition and retention which have implications for both traditional and nontraditional students.

Pro-active Initiatives:

Acknowledging the changing demographics of Indiana and in its student community, the faculty of Surmit christian College approved bold initiatives with regard to calendar and schedule. at the faculty meeting of August 23 . 1989 (Exhibit II), the faculty approved--and the Board of Governors endorsed on September 22, 1989 (Exhibit III)--a 14-2-2-14 calendar. This calendar approach permits innovative, modular courses in the two week post/preterm. Moreover, for traditional and nontraditional students confronting financial challenges, this calendar makes available mid-year work time.

Second, the faculty approved an expansion of evening offerings. Sumit A.D. (after lark) debuted in Spring 1990. As the curriculum develops it will be possible to complete an Associate of Arts program in the evenings. Further, with the initiation of "divisional" majors (approved December 7, 1989, (see Exhibit IV) a degree completion option in General studies will also arise.

Third, to enhance accessibility for traditional and nontraditional students, the day schedule of classes has also been innovatively addressed. Classes will be held 8:00 A.M.-5:00 P.M. Monday, Kednesday, Thursday. Tuesdays and 
Page -2-

123

Institutional Development Proposal, 1990

Fridays will be available for modular classes to increase access for nontraditional and mitigate their comitments to campus.

Further, the changes in calendar and schedule make possible weekend college. In the Fall of 1990, Friday evening/saturday modules will begin. Semester credit coürses will be taught in Eive to six week modules. As curriculum is developed, associate programs and the baccalaureate in General Studies will be possible in this format.

Pro-actively, then, through calendar, evening, day schedule, and weekend modules the College endeavors to address the needs of the traditional and nontraditional matriculant.

Problem statement:

The creative initiatives of the Sumit faculty which make educational experience available through various delivery paradigms emphasizes the College's commitment to both traditional and nontraditional student. Yet, attrition and retention are key concerns. As Robin Wilson observes in the Chronicle of Higher Education (2/21/90), only $15 \%$ of College matriculants complete degrees within four years. And, less than 50\% complete degrees in six years. These national statistics heighten the campus concern for creative response to attrition and pro-active programs Eor retention.

The College believes that an audit of attrition/retention is necessary as it endeavors to deal with demographic change and new calendar and delivery initiatives. An analysis of 1985 recruited matriculants (Exhibit $V$ ) reveals serious challenges. The College loses $62 \%$ of its freshmen prior to Sophomore enrollment. Further, the yeoman work of the College admissions personnel in recruiting 220 students for the 1989-90 year (Exhibit VI) evidences that optimum growth may not occur without expert attention to the attrition/retention issues.

The widely recognized Noel/Levitz Group (Exhibit VII) audits institutional attrition and retention making recommendation for action (cost $\$ 4,500$ ). Further, on the basis of the analysis, it is wise to implement audit recommendations to improve retention of current students and those recruited for Fall 1990. We believe that support of "disadvantaged" at risk, and nontraditional students would cost $\$ 12,000$ in the first year.

In sumary, the College, responsive to the protocols of the Institutional Development program and creative in addressing demographic changes, respectfully requests $\$ 8250$ to assess and respond to issues in attrition and retention. The College will commit $\$ 8250$ in its Retention line budget to advancing this program in addition to the costs incurred by calendar, schedule, and curricular changes reviewed above.

Evaluation: 
Page -3-

Institutional Development Proposal, 1990

Steady success marks Sumit Christian College's enroliment pattern in recent years. (Indeed, as noted, a 18 increase in headcount was realized from Eall 1989 to Spring 1990). Certainly, upgraded publications, enhanced advertising, stabilized admissions staff, computer managed letter-flow and telemariceting are significant to that success. Yet, to benefit from increased recruitment the college must address attrition and retention. such assessment is especially needful as the College introduces to meet the needs of traditional and nontraditional students.

our own research shows a significant attrition/retention challenge. An Audit by Noel/Levitz is invaluable in developing means for growth through returning students. Seed funding to implement retention recommendations which address "disadvantaged," "at risk," and nontraditional students is expedient.

Funding Proposal and Budget Surumary:

As Sumit Christian college experiences steady growth in enrollment; it notes opportunities and challenges. Given the consistent stress of budget, the College's commitment of $\$ 8250$ to the attrition/retention assessment is significant. (Costs for calendar, curricular, and delivery changes are being borne by the operating budgets of 1989-90, 1990-91.) The partnership of the Institutional Development program enables us to assess and respond to the attrition/retention issue as a part of demographic change.

Institutional funding:

Administration Marketing/Enrollment Retention

FY 1989-90

1000

Projected 1990-91

$1-1-0525-5250$

PROGRAM EXPENSES:

Noel/Levitz Audit:

4,500

Audit Implementation $\quad 12,000$

Total

16,500

\begin{tabular}{cr} 
(College Support) & 8,250 \\
Grant Request & 8,250 \\
\hline
\end{tabular}

Sumit Christian college respectfully requests an Institutional Development grant of $\$ 8,250$ to address and respond pro-actively to issues in attrition and retention. In so doing the college may enhance its service to disadvantaged, at risk, and nontraditional students.

DGL9824: ir 


\section{NOEL/LEVITZZ}

902 East Second Avonue, Coralville, Lowa 52241

(319) $337-4700$. FAX (319) 337-5274

February 26. 1990

Dr. David Lalka

Vice President for Development

Summit Christian College

$1025 \mathrm{~W}$. Rudisill

Fort Wayne, IN 46807

Dear David,

Thank you for the opportunity to respond to your recent inquiry regarding a Noel/Levitz Strategic Enrollment Analysis. Our belief, David, is that the challenge colleges and universities face is not simply to enroll students initially, but to get them to want to re-enroll voluntarily. We at Noel/Levitz take great pride in assisting institutions achieve lasting enrollment results through sound recruitment and retention practices designed to enroll "graduates-to-be" not just "freshmen-to-be."

On the basis of our recent conversation, we find ourselves excited about the opponunity of working with Summit Christian College. Since we share with you so completely the powerful mission of assisting students in achieving their potential, we feel a great commitment to helping your school foster student success and growth.

Our approach is based on the premise that true enrollment development is built upon lasting forms of institutional effectiveness. The process begins with an acknowledgement that the way Summit Christian College recruits students today influences its ability to retain and serve those students tomorrow. Likewise, we find that retention success is a pre-requisite for long-term recruiting success since satisfied students and graduates have an enormous impact on an institution's ability to recruit new students.

Our goal is to help you put in place those systems which attract and retain the best and most desired prospects for Summit Christian College. We are confident that Noel/Levitz Centers can help you implement a program to recruit "graduates-to-be" through a better understanding of your position in the academic marketplace and the use of state-of-the-art communication strategies and tactics. We can also provide the guidance necessary to achieve a dramatic difference in the level of student satisfaction at Summit Christian College and. thereby, a significant increase in student retention.

We are confident that the experience we have had with over 560 public and private institutions will provide the base of knowledge in working with the special characteristics and markets of your school. We have seen a large private institution increase its total enrollment by nearly $20 \%$. A prestigious public institution has reported a $15 \%$ enrollment increase. Many smaller private church-related institutions as well as two-year community colleges have indicated equally impressive enrollment tum-arounds. Although the experience in a paricular school will vary, we have come to expect a 20\% enrollment inctease over four years and/or a $33 \%$ decrease in the attrition rate within three years as an institution puts forth the effort to fully implement the plans and strategies we have found to be so effective in the student market place.

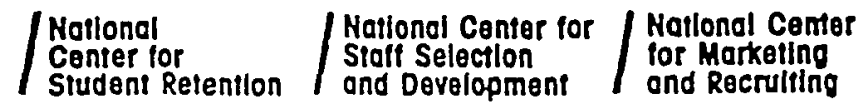


In the attached proposal. I have detailed an action plan for either a full Strategic Enrollment Analysis--which includes an audit of both recruitment and retention efforts-or an audit limited to either program. We recommend the full Strategic Enrollment Analysis since it provides a complete picture of your total enrollment situation (and provides to you some economies).

However, we understand fiscal limitations and will work with you in any way we can to provide as comprehensive a review as possible within whichever option you choose. We pride ourselves in customizing our services to the needs of the client. Far too often we encounter institutions which have been sold a standard package that is not flexible and does not meet their needs. After you have had a chance to review the enclosed proposal, we would be glad to incorporate modifications so that it more completely reflects your expectations.

I look forward to the opportunity to work with you and Summit Christian College. If you have any questions or if there is any way we can provide additional information, please give me a call.

Sincerely.

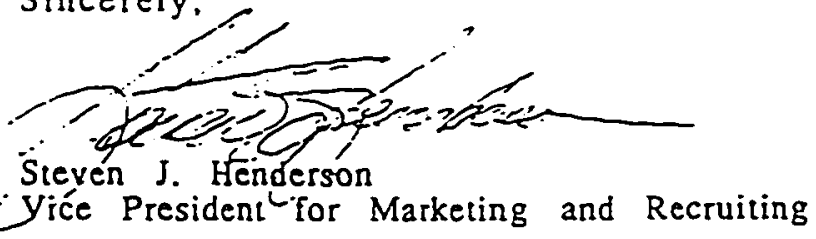

Enclosure

P.S. I have enclosed a few extra copies of our Recruitment-Plus and RetentionPlus brochures. They may be useful tools for explaining the wide range of services available from Noel/Levitz Centers. 


\title{
NOEL/LEVITZZ
}

\section{STRATEGIC ENROLLMENT ANALYSIS ${ }_{\text {TM }}$ FOR}

\author{
SUMMIT CIHRISTIAN COLIEGE
}

\section{Our Approach: Discovery, Development, Direction}

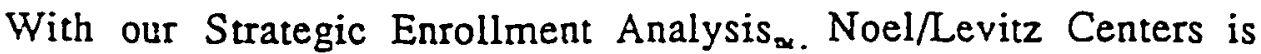
prepared to help Summit Christian College in a number of highly central areas. The following proposal covers all dimensions of this service, and allows your institution to choose the entire Strategic Enrollment Analysis or that part which is most applicable.

Our efforts at Summit Christian College will be based on an in-depth study of your enrollment conditions and marketing practices. The Noel/Levitz Strategic Enrollment Analysis tu $_{\text {ix }}$ is an action oriented, diagnostic package [including the $\mathrm{N} / \mathrm{L}$ Recruiting/Marketing Audit and the N/L Retention Audit] that examines the potential of Summit Christian College for improved performance in the areas of (1) student marketing and recruitment and (2) student retention. Noel/Levitz Centers conducts a rapid but thorough evaluation of your current efforts and helps you identify opportunities for greater effectiveness based both on your institution's strengths and on proven marketing and retention strategies.

As we have shown at over 560 institutions, recruitment and retention are inextricably inter-related. We want to assist Summit Christian College in increasing its voluntary re-enrollment as well as its new student draw and "fit." We take great pride in providing sound strategies to help you recruit "graduates-to-be" not just "freshmen-to-be." For this reason we recommend that you consider the total Noel/Levitz Strategic Enrollment Analysis ${ }_{n}$.

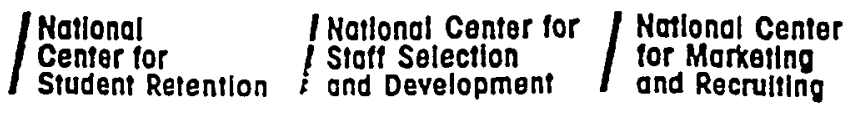


Strategic Enrollment Analysis

Proposal for Summit Christian College

February 26, $1990 \quad$ Page 2

For the Strategic Enrollment Analysis at Summit Christian College, our senior staff in marketing, recruiting, and enrollment development will:

Marketing and Recruiting:

- Evaluate current enrollment management techniques and approaches

- Assess the effectiveness of current admissions publications, and discuss approaches toward writing publications which are more student-directed

- Assess the quantity and quality of student contact at each phase of the enrollment process

- Review advertising and promotional strategies

- Analyze current market research available as well as any related data or documents

- Assess the use of financial aid in enrollment management and student marketing

- Review the use of enrollment management professional and support staffing.

Retention:

- Determine factors that affect who stays, who leaves, and what makes the difference

- Review the effectiveness of those critical entry services such as orientation, registration, advising, course placement, academic support services, career planning, etc.

- Assess your institutional strengths and areas in need of further development -- in relation to attrition

- Assess present student retention activities, practices and programs that have an impact on student satisfaction and retention

- Assess "user-friendliness" of campus approaches and practices that may have an impact on student retention. 
Strategic Enrollment Analysis

Proposal for Summit Christian College

February 26, $1990 \quad$ Page 3

Based on this information, we will assess where your efforts can be best directed and where changes need to be made. In addition, we will:

- Create broad awareness that enrollment development-: recruitment and retention--is a campus-wide responsibility

- Describe the latest "state-of-the-art" practices that attract and retain students

- Destroy the myth that increasing retention means lowering standards

- Provide insights to faculty and staff members about their role in recruiting and retaining students

- Share the latest changes and developments in the academic marketplace

- Provide a customer service staff development/training experience for clerical and technical support staff

- Enlighten key individuals about the "state-of-the-art" inenrollment management and ways of activating collegewide resources

- Identify potential target audiences and effective communication approaches to be used with each constituency

- Build momentum for an organized, campus-wide retention effort

- Outline priorities for the next steps--data collection, program development, and policy and program changes--to increase institutional effectiveness. 
Strategic Enrollment Analysis

Proposal for Summit Christian College

February 26, $1990 \quad$ Page 4

\section{The Outcome: A Foundation for Future Actions}

Noel/Levitz Centers is dedicated to providing sophisticated, useful, and useable services for institutions of higher education. You can be assured that the report which follows the on-site visit will be just that. Through our.Strategic Enrollment Potential Report we will develop specific directions, action recommendations and policy proposals for future enrollment development and retention activities--as well as identifying any additional areas of college operations in need of study.

The Strategic Enrollment Potential Report will in a very succinct manner provide:

- Specific direction on ways to increase or maintain enrollment at optimum levels

- The component ideas for developing and improving your marketing and recruitment plan

- A careful analysis of your:

- recruitment publications

- use of staff

- communications flow

- office systems

- prospect identification and cultivation strategies

- computer use

- financial aid resources

- orientation program

- academic advising system;

- An Executive Summary of retention forces and potential for improvement on your campus

- Identification of the critical factors that are contributing to attrition on your campus

- A delineation of programs, services and interventions that will have the greatest impact on reducing dropout rates on your campus

- An outline for mobilizing and organizing a campus-wide retention effort. 
Strategic Enrollment Analysis

Proposal for Summit Christian College

February 26, 1990

Page 5

The Campus-wide Awareness Workshops, designed for all faculty, staff, and administrators, can be customized from the following menu of topics:

- Emerging Indicators of Institutional Quality and Effectiveness

- The Changing Academic Marketplace

- Advanced Recruitment and Retention Practices

- Lowering Standards is Not the Answer

- College Faculty as Key Enrollment Agents

- Front Line Clerical and Technical Staff as Critical Retention Agents

- Academic Advising Concepts, Skills and Techniques Cornerstones of Student Enrollment

- Attracting and Retaining Under-represented Populations

- Attracting and Retaining Non-traditional Age Students

- Implementing Changes and Making Them Work

- Others, as deemed pertinent. 
Strategic Enrollment Analysis

Proposal for Summit Christian College

February 26, $1990 \quad$ Page 6

\section{SEA Summary}

The components for the Strategic Enrollment Analysis are as follows:

a. Recruiting/Marketing Audit -- $\$ 4,500$

Pre-visit review; two day on-campus consultation including assessment of all systems, publications, procedures and plans relating to student recruitment and a $1 / 2$ day campus-wide awareness workshop on applicable marketing issues; and a 6-10 page Strategic Enrollment Potential Report on Recruiting/Marketing summarizing the results of the audit and pin-pointing strategies and changes with the greatest promise for enhancing the marketing potential of your institution.

b. Retention Audit -- $\$ 4,500$

Pre-visit review; two day on-campus consultation including assessment of "customer service environment" and academic support services, processes and strategies most relevant to retaining students and a $1 / 2$ day campus-wide awareness workshop for both professional and support staff in customer service and relevant retention issues; and a 6-10 page Strategic Enrollment Potential Report on Retention summarizing the results ofthe audit and pin-pointing strategies and changes with the greatest promise for enhancing the retention potential for your institution.

If the full Strategic Enrollment Analysis is desired for the main campus, the combined price is $\$ 8,400$. The only additional costs that would be the responsibility of the college would be for lodging, meals, and the most reasonable available transportation for any trip to campus. 
Strategic Enrollment Analysis

Proposal for Summit Christian College

February 26, $1990 \quad$ Page 7

\section{Firm Qualifications}

Noel/Levitz Centers for Institutional Effectiveness Inc. is an educational consulting firm specializing in college management consultation and enrollment development in the areas of marketing, recruitment, and retention. Our services range from the most highlyfocused consulting and problem-solving in each of these areas to highly-integrated, system-wide evaluations of institutional need. In our work at the local, state, and national level, and in our direct consultation with more than 560 post-secondary educational institutions nationwide, we have earned an outstanding reputation for serving colleges and universities. Through campus consultations and presentations in the last three years alone, Noel/Levitz Centers has directly improved learning and living environments for over $1,000,000$ college students throughout the country.

Some of our clients have come to us for highly-focused services, such as increasing their ability to recruit and retain high ability students, assess the needs of adult learners, or train department heads and program directors to more effectively select and develop college teachers.

Other clients have come to us for more extensive consultations and services. At such institutions, we provided image assessment; evaluation of student satisfaction audits of all campus systems affecting retention and recruitment; and presented programs in faculty/staff development.

Yet other clients have hired us to provide more extensive services still. Our comprehensive evaluation and enrollment development package has also included mission and image development, market research, the development of recruiting publications, the initiation of computer-based telemarketing systems, and on-going help with longrange strategic planning. 
Strategic Enrollment Analysis

Proposal for Summit Christian College

February 26, $1990 \quad$ Page 8

The architects for Noel/Levitz Centers' direction and success are its co-founders, Dr. Lee Noel and Dr. Randi Levitz. They are recognized as national leaders in the areas of educational management and enrollment development and retention, and together have published numerous ground-breaking books and articles, including the state-of-the art work, Increasing Student Retention: Effective Programs and Practices for Reducing the Dropout Rate (Jossey-Bass, Inc., 1985).

Supporting the work of the principal consultants at Noel/Levitz Centers, Inc., is a team of professional strategies in marketing, recruiting, enrollment development, and institutional effectiveness. The company employs specialists in recruitment systems, retention and analytic tools. The staff prossesses expertise in a blend of disciplines, enabling Noel/Levitz Centers to respond constructively, creatively and realistically to its clients' needs, and to improve the educational experience for hundreds of thousands of students every year.

Noel/Levitz Centers, Inc. has extensive and successful experience in analyzing marketing, recruiting, and retention systems, and in developing pragmatic policy proposals and action recommendations for college and university administrators. The design for this project comes out of this foundation of knowledge and experience, and reflects our judgement about what will work and what it will take to get results for Summit Christian College. We at Noel/Levitz Centers stand ready to assist you. 
R E F E R E N C E I I S T 
Astin, A. (1975). Preventing students from dropping out. San Francisco: Jossey-Bass.

Beal, P., \& Noel, L. (1980). What works in student retention. The Report of a Joint Project of the American college Testing Program and the National Center for Higher Education Management Systems. Hunt Valley, MD: ACT Production Team.

Beidler, P. (1990). Loving teaching. Journal on Excellence in college Teaching, $1,1-8$.

Brownfield, K. (1993). The relationship between the Myers-Briggs Personality Types and learning styles. Portales, NM: Eastern New Mexico University.

Cabrera, A., Nora, A., \& Castaneda, M. (1993). College persistence: Structural equations modeling test of an integrated model of student retention. Journal of Higher Education, 64(2), 124-139.

Cash, W., \& Bissel, L. (1985). Test Tinto's Model of Attrition on the Church-Related Campus. A paper presented at the Annual Forum of the Association for Institutional Research, Portland, OR.

Coan, R. (1978). In Oscar Krisen (Ed.), The eighth mental measurements yearbook. Lincoln, NE: The University of Nebraska.

Cope, R. (1978). Why students stay, why they leave. In L. Noel (Ed.), Reducing the drop-out rate: New directions for student services (pp. 1-11). San Francisco: Jossey-Bass.

Cope, R., Hannah, W. (1975). Revolving college doors. New York: John Wiley \& Sons.

Cross, P. (1990). Teaching to improve learning. Journal of Excellence in College Teaching, 1, 9-22. 
Dale, P. (1995). A successful college retention program. Report of the HORIZONS student support Program, Purdue University, IN. (ERIC Document Reproduction Service No. ED 380 017)

Devito, A. (1985). Review of the Myers-Briggs Type Indicator. In James $V$. Mitchell (Ed.), The ninth mental measurement yearbook (pp. 1030-1032). Lincoln, NE: The University of Nebraska.

Ferguson, G. (1981). Statistical analysis in psychology and education ( 5 th ed.). New York: McGraw-Hill Book Company.

Fischbach, R. (1990). Persistence among full-time students at Illinois central college. East Peoria, IL: Illinois central college.

Friday, R. (1988) . Create your college success. Belmont, CA: Wadsworth Publishing Company.

Gardner, J., Jewler, J. (1985). College is only the beginning. Belmont, CA: Wadsworth Publishing Co.

Gardner, J., Jewler, J. (1989). College is only the beqinning (2nd ed.). Belmont, CA: Wadsworth Publishing Company.

Henderson, S. (1990). Retention consultation for Summit Christian College. Coralville, IA: Noel/Levitz Centers for Institutional Effectiveness and Innovation.

Hovland, M. (1990). Retention consultation for summit Christian College. Coralville, IA: Noel/Levitz Centers for Institutional Effectiveness and Innovation.

Jung, C. (1974). Psychology of personality: Readings in theory. In William S. Sahakian (Ed.), Psychology of personality: Readings in theory (pp. 69-73). Chicago: Rand McNally College Publishing Co.

Kalsbeek, D. (1989). Linking learning style theory with retention research: The Trails Project. Tallahassee, FL: Florida State University, Association of Institutional Research.

Kalsbeek, D. (1990). Tracking retention and academic integration by learning styles: The Trails Project. st. Louis, MO: st. Louis University, office of student Life studies. 
Kalsbeek, D. (1990). Campus retention patterns: The MBTI in institutional self-studies. st. Louis, Mo: st. Louis University, office of Student Life Studies.

Keirsey, D., \& Bates, M. (1984). Please understand me. Del Mar, CA: Prometheus Nemesis Book Company.

Kroeger, O., \& Thuesen J. (1988). Type talk. New York: A Tilden Press Book.

Lalka, D. (1990, March 1). Institutional Development Proposal: Admission/Retention Committee Report. Fort Wayne, IN: Fort Wayne Bible College (Renamed summit Christian college).

Lenning, O., Mohnkern D. (1986). Decreases in freshmen attrition: We can make it happen and WE can help: A study of student retention at Roberts Wesleyan College. Paper presented at the Annual Forum of the Association for Institutional Research, Orlando, FL.

Martin, C. \& Boyce, D. (1989). Strategies for success at King College. Bristol, TN: King College.

Martin, C., Berkey, L., \& Gribbin, K. (1982). Small college retention: A study and proposal for survival. content Program presented at the American Personnel and Guidance Association Annual Convention, Detroit, MI.

Millard, B. (1988, April 2). Program smooths transition. Bristol Herald courier/Virginia-Tennessee.

Myers, I., Mccaulley. (1985). Manual: A quide to the development and use of the Myers-Briggs type indicator. Palo Alto, CA: Consulting Psychologist Press.

O'Conner, J. (1993). Use of the M-BTI as a Predictor of Successful Academic and Military Performance at the United States Coast Guard Academy. Report 1993, Coast Guard Academy, New London, CT, Center for Advanced Studies. (ERIC Document Reproduction Service No. ED 367 672)

Pedhazur, E. (1982). Multiple regression in behavioral research (2nd ed.). New York: Holt, Rinehart and winston.

Sax, G. (1980). Principles of educational and psychological measurement and evaluation (2nd ed.). Belmont, CA: Wadsworth Publishing Company. 
Starke, M. (1994). Retention, bonding, and academic achievement: Effectiveness of the college seminar in promoting college success. Presented at the 13th Annual Freshman Year Experience National Conference, Columbia, SC.

Summit Christian College. (1981, March 25). Minutes of the Admissions/Retention Committee, Fort Wayne, IN.

Summit Christian College. (1989). Retention. Compiled by the Admissions/Retention Committee, Fort Wayne, IN.

Summit Christian College. (1990, November 29). Minutes of the Admissions/Retention Committee, Fort Wayne, IN.

Summit Christian College. (1990). Chart of Retention studies, Fort Wayne, IN.

Swartzwelder, C. (1989). College success program--

Atlantic Christian College. Wilson, NC: Atlantic Christian college.

Tharp, G. (1993). The connection between personality type and achievement in college Biology: How our personality influences our ability to succeed in science. Journal of College Science Teaching, 276278 .

Tinto, V. (1987). Leaving college. Chicago: The University of Chicago Press.

Upcraft, I., Garland, P., Finney, J. (1984). Orienting students to college. San Francisco, CA: Jossey-Bass.

Walter, T., \& siebert, A. (1987). student success (4th ed.). New York: Holt, Rinehart and Winston.

wiggins, J. S. (1989). Review of The Myers-Briggs Type Indicator. In J. Conoley \& J. Kramer (Eds.), The tenth mental measurement yearbook (pp. 537-538). Lincoln, NE: The University of Nebraska.

Wilson, R. (1990, February 21). Only 15\% of students graduate in 4 years, a new study finds. Chronicle of Higher Education, 36(23), A1, A42.

Wu, s. (1992). Education and learning in schools with high dropout rates. Washington, DC: National Center for Education statistics. 
VITA

C. Joseph Martin
6009 Holley Oak Drive
Fort Wayne, Indiana 46818
Work Phone: (219) 456-2111 $\quad$ Home Phone: (219) 489-8870

EDUCATION :

Doctor of Education, Andrews University, 1996

Doctor of Ministry, Union Theological Seminary, 1974

Master of Arts, Saint Mary's College, 1968

Master of Religious Education, Goshen College Biblical Seminary, 1965

Bachelor of Divinity, Goshen College Biblical Seminary, 1960

Bachelor of Arts, Bethel College, 1957

Additional Studies: East Tennessee State University

University of Virginia

University of New Mexico

Grace Theological Seminary

WORK HISTORY:

Associate Professor of Psychology, Taylor University

Fort Wayne Indiana Campus, 1990 - present

Director of Counseling, King College, Bristol, TN., 1985-1990

Vice-President of Student Affairs and Associate Professor of Psychology, Bethel College, Mishawaka, IN, 1980-1985

Director of Counseling, Davis and Elkins College, Elkins, WV, 1968-1980

Additional experiences: Special Reading Teacher, Professor of Bible, Principal/Teacher, Profit Planning Business, and Farmer

WRITING :

Handbook for High Risk College Freshmen Emphasis Magazine

A Career/Life Planning Experience, Co-author

High Risk Freshmen in Measurement and Evaluation, Coauthor 
PROFESSIONAL CERTIFICATION:

National Certified Counselor

Certified Family Life Educator

Pastoral Evaluator Specialist

PROFESSIONAL MEMBERSHIPS

American Counseling Association

National Career Development Association

Association for Religious and Value Issues in Counseling

Indiana Counseling Association

American Association of Christian Counselors

Indiana Academy of Science 